\title{
Phylogenetics-based identification and characterization of a superior 2,3-butanediol dehydrogenase for Zymomonas mobilis expression
}

Venkataramanan Subramanian ${ }^{1 *} \mathbb{0}$, Vladimir V. Lunin ${ }^{1 *+}$, Samuel J. Farmer ${ }^{1}$, Markus Alahuhta ${ }^{1}$, Kyle T. Moore $^{1}$, Angela Ho ${ }^{1}$, Yogesh B. Chaudhari ${ }^{1,2}$, Min Zhang ${ }^{1}$, Michael E. Himmel ${ }^{1}$ and Stephen R. Decker ${ }^{1}$

\begin{abstract}
Background: Zymomonas mobilis has recently been shown to be capable of producing the valuable platform biochemical, 2,3-butanediol (2,3-BDO). Despite this capability, the production of high titers of 2,3-BDO is restricted by several physiological parameters. One such bottleneck involves the conversion of acetoin to 2,3-BDO, a step catalyzed by 2,3-butanediol dehydrogenase (Bdh). Several Bdh enzymes have been successfully expressed in Z. mobilis, although a highly active enzyme is yet to be identified for expression in this host. Here, we report the application of a phylogenetic approach to identify and characterize a superior Bdh, followed by validation of its structural attributes using a mutagenesis approach.
\end{abstract}

Results: Of the 11 distinct bdh genes that were expressed in Z. mobilis, crude extracts expressing Serratia marcescens Bdh (SmBdh) were found to have the highest activity $(8.89 \mu \mathrm{mol} / \mathrm{min} / \mathrm{mg})$, when compared to other Bdh enzymes $(0.34-2.87 \mu \mathrm{mol} / \mathrm{min} / \mathrm{mg})$. The $\mathrm{SmBdh}$ crystal structure was determined through crystallization with cofactor (NAD ${ }^{+}$) and substrate (acetoin) molecules bound in the active site. Active SmBdh was shown to be a tetramer with the active site populated by a Gln247 residue contributed by the diagonally opposite subunit. SmBdh showed a more extensive supporting hydrogen-bond network in comparison to the other well-studied Bdh enzymes, which enables improved substrate positioning and substrate specificity. This protein also contains a short a6 helix, which provides more efficient entry and exit of molecules from the active site, thereby contributing to enhanced substrate turnover. Extending the a6 helix to mimic the lower activity Enterobacter cloacae (EcBdh) enzyme resulted in reduction of $S m B d h$ function to nearly $3 \%$ of the total activity. In great contrast, reduction of the corresponding a6 helix of the EcBdh to mimic the SmBdh structure resulted in $\sim 70 \%$ increase in its activity.

Conclusions: This study has demonstrated that SmBdh is superior to other Bdhs for expression in Z. mobilis for 2,3$\mathrm{BDO}$ production. SmBdh possesses unique structural features that confer biochemical advantage to this protein. While coordinated active site formation is a unique structural characteristic of this tetrameric complex, the smaller a6 helix and extended hydrogen network contribute towards improved activity and substrate promiscuity of the enzyme.

\footnotetext{
*Correspondence: venkat.subramanian@nrel.gov; vladimir.lunin@nrel.gov

†Venkataramanan Subramanian and Vladimir V. Lunin contributed equally to this work

1 Biosciences Center, National Renewable Energy Laboratory, 15013

Denver West Parkway, Golden, CO 80401, USA

Full list of author information is available at the end of the article
}

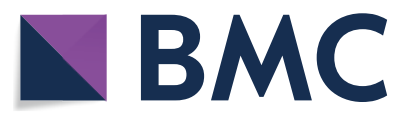

(c) The Author(s) 2020. This article is licensed under a Creative Commons Attribution 4.0 International License, which permits use, sharing, adaptation, distribution and reproduction in any medium or format, as long as you give appropriate credit to the original author(s) and the source, provide a link to the Creative Commons licence, and indicate if changes were made. The images or other third party material in this article are included in the article's Creative Commons licence, unless indicated otherwise in a credit line to the material. If material is not included in the article's Creative Commons licence and your intended use is not permitted by statutory regulation or exceeds the permitted use, you will need to obtain permission directly from the copyright holder. To view a copy of this licence, visit http://creativeco mmons.org/licenses/by/4.0/. The Creative Commons Public Domain Dedication waiver (http://creativecommons.org/publicdomain/ zero/1.0/) applies to the data made available in this article, unless otherwise stated in a credit line to the data. 
Keywords: Butanediol dehydrogenase, Serratia marcescens, Acetoin, 2,3-Butanediol, Crystallography, Phylogenetics

\section{Background}

Petroleum alternatives are critical to maintaining a sustainable economy while satisfying the ever-growing global energy demands. Diols, potentially renewable compounds containing two hydroxyl groups, have wide-ranging applications in chemicals and fuels. 2,3-butanediol (2,3-BDO) is exemplar of industrial diols having been used in liquid fuels, cosmetics and drugs, paints, food additives, and synthetic rubber $[1$, 2].

With two chiral centers, three isomers of 2,3-BDO are possible. The levo $(2 R, 3 R)$ and dextro $(2 S, 3 S)$ isomers are optically active, whereas the meso $(2 R, 3 S)$ isomer is not $[3,4]$. Biological synthesis of 2,3-BDO occurs via three enzymatic conversion steps $[5,6]$. The first step involves condensation of two pyruvate molecules by the acetolactate synthase (Als) in a single decarboxylation reaction to produce $\alpha$-acetolactate. A second decarboxylation step catalyzed by the enzyme acetolactate-decarboxylase produces acetoin. In the presence of NADH, acetoin is reduced to 2,3-BDO by the enzyme butanediol dehydrogenase (Bdh). Under aerobic conditions, the acetoin spontaneously converts to diacetyl, which can be reconverted to acetoin by diacetyl reductase and subsequently reduced to 2,3-BDO. Depending on oxygenation conditions, (3R)-acetoin or (3S)-acetoin is preferably produced by microorganisms. (3R)-acetoin is the product of anaerobic fermentation from acetolactate. However, under aerobic conditions, (3S)-acetoin is produced from diacetyl [7]. Depending on the type of acetoin used, three different stereoisomers of 2,3-BDO, (2R, 3R)-BDO, (2R-3S)-BDO, and $(2 \mathrm{~S}, 3 \mathrm{~S})-\mathrm{BDO}$ are produced [8].

Several bacteria, including Klebsiella sps. Enterobacter sps., Pseudomonas sps., Serratia sp., and Bacillus sps. are known to naturally produce 2,3-BDO. Interestingly, the highest 2,3-BDO concentrations are produced by risk group 2 organisms and are thus not desirable for large-scale production [4, 9]. Organisms, such as Escherichia coli, Lactobacillus lactis, Synechococcus elongatus, and even yeasts such as Saccharomyces cerevisiae have been engineered to produce 2,3-BDO. The 2,3-BDO titers reported are 73.8, 51, 2.38, and $154.3 \mathrm{~g} / \mathrm{L}$, respectively, for these organisms [10-13].

Zymomonas mobilis is known primarily for its ethanologenic properties. In comparison to yeasts, which use the Entner-Meyerhof-Parnas pathway for glycolysis, Z. mobilis uses the Entner-Doudoroff (ED) pathway. The ED pathway is found in facultative anaerobes and aerobic microorganisms, leading to higher ethanol yields [14]. Z. mobilis has other advantages, such as high alcohol and $\mathrm{pH}$ tolerance, high rate of sugar uptake, low biomass production, and reduced aeration requirement thereby reducing the production costs [15]. Interestingly, Z. mobilis is capable of using both deacetylated-disc refined (DDR) and deacetylatedmechanically refined (DMR) sugar streams for ethanol production [16]. Recently, it was also demonstrated by our laboratory that the ethanol flux could be diverted to 2,3-BDO using pure or mixed sugars as substrates. By introducing the three 2,3-BDO pathway genes followed by promoter replacements and fermentation condition optimizations, the 2,3-BDO titers of $>13 \mathrm{~g} / \mathrm{L}$ was achieved [15].

One of the bottlenecks for production of 2,3-BDO in $Z$. mobilis is the competition between NADH oxidase (Ndh) and Bdh to oxidize NADH to $\mathrm{NAD}^{+}$under oxic conditions. This is in addition to the NADH demand for glycerol and ethanol production by this organism. Depending on the activity of the Bdh enzyme, the conversion of NADH could be shifted towards 2,3-BDO production instead of the respiratory chain. The conversion of acetoin to 2,3-BDO by $\mathrm{Bdh}$ is a reversible reaction governed by the $\mathrm{pH}[17,18]$.

$$
\text { Acetoin }+\mathrm{NADH}+\mathrm{H}^{+} \leftrightarrow 2,3 \text {-butanediol }+\mathrm{NAD}^{+}
$$

Bdh enzymes can be classified into R-acting or S-acting depending on the chirality of the chiral center introduced by the enzyme at the acetoin $\mathrm{C} 2$ atom. Whereas the preference for (3R)-acetoin or (3S)-acetoin is imprinted in the geometry of the substrate-binding pocket, R-acting and $\mathrm{S}$-acting Bdh enzymes belong to different protein families and possess different architectures. Recently, the first structure of an R-acting Bdh from Bacillus subtilis was deposited to the Protein Data Bank (PDB, www.rcsb.org, [19]) with the PDB ID 6IE0, while there are numerous structures available for other members of the mediumchain dehydrogenase/reductase (MDR) superfamily [2023]. Examples of R-acting Bdh enzymes are those from S. cerevisiae, Paenibacillus polymyxa, B. subtilis, Pseudomonas putida, and Bacillus licheniformis [24-27].

$\mathrm{S}$-acting Bdh enzymes belong to the short-chain dehydrogenase/reductase (SDR) superfamily of proteins [28]. The substrates for this superfamily of enzymes vary greatly in size and include glucose, alcohols, and steroids [29]. These enzymes are well studied and several S-acting Bdhs are characterized structurally, such as those of (3R)-acetoin-dependent S-acting Bdh from Klebsiella 
pneumoniae (PDB ID 1GEG, deposited in 2001) and (3S)acetoin-dependent S-acting Bdh from Corynebacterium glutamicum (PDB ID 3A28, deposited in 2010) reported by Otagiri and colleagues [30,31].

In this work, we have focused on identifying the most active Bdh enzyme that can function in $Z$. mobilis using a phylogenetics approach to enable efficient conversion of acetoin to 2,3-BDO. Furthermore, we have obtained the crystal structure of the Serratia marcescens Bdh (SmBdh) by expressing it in this industrially relevant host and provided comparative analysis against similar Bdh enzymes. We have also carried out structurally guided changes to $S m B d h$ to explain its superiority over lower activity Bdh enzymes from the same family of proteins, followed by biochemical confirmation of the activity of the designed mutants.

\section{Results and discussion}

Production of 2,3-BDO is dependent on several factors, some of which include the types of heterologous 2,3BDO pathway genes used, the levels of oxygen present, the presence of competitive pathways, such as ethanol and glycerol, as well as competing enzymes for NADH conversion. We have concentrated on only one of these parameters, namely the activity of the NADH-consuming enzyme, Bdh, that can compete with Ndh in the presence of oxygen. This biochemical step is considered as one of the bottlenecks in 2,3-BDO production by this organism [15]. Although Z. mobilis has been shown to express several commonly known Bdh enzymes [15], there has been no comprehensive study undertaken to express functional Bdhs from diverse species that could contribute towards improving 2,3-BDO production in this organism. We therefore decided to take a phylogenetic approach to this problem by screening Bdh enzymes across different bacterial kingdoms to identify the best active enzyme that could be engineered in this organism.

\section{Identification of butanediol dehydrogenase sequences for expression in Z. mobilis}

A total of 57 protein sequences were included in the list of Bdh for phylogenetic analysis. This list included two sequences each from Azotobacter vinelandii, Acidovorax avenae, Rhodococcus jostii, and Agrobacterium tumefaciens. These sequences belonged to two different classes of Bdh proteins based on their protein sequence lengths. Bifidobacterium asteroides contained three Bdh sequences, two belonging to the short length class and one belonging to the long class. We also included $B$. subtilis, B. licheniformis, K. pneumoniae, E. cloacae, and $S$. marcescens, studies for which expression has been carried out in E. coli [13]. Clearly, two distinct clusters were observed on the phylogenetic tree, one cluster (21 sequences) primarily contained the "short length" Bdhs, while the other (36 sequences) contained the "long" Bdhs (Fig. 1). The "short length" Bdh cluster comprised $\mathrm{S}$-acting enzymes (presumably belonging to the SDR superfamily), such as $K$. pneumoniae, E. cloacae and S. marcescens [18, 32, 33]. The "long" Bdh cluster comprised R-acting enzymes (presumably belonging to the MDR superfamily), such as $B$. subtilis and $C$. beijerinckii [33]. Each of these two major clusters were further subdivided into smaller sub-clusters. Based on their clustering pattern, we subdivided the "short length" clusters into two sub-clusters, while subdividing the "long" class of Bdhs into five sub-clusters. Eight protein sequences were selected from the "long" and three sequences were selected from the "short-length" clusters, such that at least one representative protein sequence was selected from each sub-cluster of the phylogenetic tree (Fig. 1).

\section{Screening of butanediol dehydrogenases for protein expression and activity in $Z$. mobilis}

The Z. mobilis strain used in this study was $9 \mathrm{C}$, which was a modified version of strain $8 \mathrm{~b}$ that was originally developed for improved ethanol production [15, 34]. The 9C strain lacked the chloramphenicol and tetracycline markers that the $8 \mathrm{~b}$ strain contained. Neither of these strains were engineered for $\mathrm{BDH}$ production. Moreover, native $Z$. mobilis does not contain the $\mathrm{BDH}$ pathway to enable 2,3-BDO production. Thus, our study was not designed to carry out expression of the entire 2,3-BDO pathway, instead it was only intended to study expression and activity of the expressed BDH enzyme in this organism. Transformants obtained from the spectinomycin selection plates were confirmed for the presence of the individual $b d h$ genes by PCR analysis. Eight individual transformants were subjected to colony PCR, results of which are shown in Additional file 1. Based on PCR analysis, five independent transformants were selected for protein expression analysis. Because these Bdh proteins were expressed without an epitope tag, we decided to use activity assays as a screen to detect protein expression in the different $Z$. mobilis transformants. The results of the activity assay are shown in Table 1 . We observed that most of the $b d h$ transformants showed an activity of $\leq 2 \mu \mathrm{mol} / \mathrm{min} / \mathrm{mg}$ using acetoin and NADH as the substrate and cofactor, respectively. This included 9 of the 11 tested $b d h$ genes (Additional file 2). We used three $Z$. mobilis strains expressing the E. cloacae, B. subtilis, and Lactococcus lactis bdh genes under the same promoter as controls for which expression and/or 2,3-BDO production has been tested in-house (unpublished data). Two of the Bdh enzymes, namely those from $M$. luteus and $S$. marcescens, showed Bdh activity of $\sim 3.0$ and $9.0 \mu \mathrm{mol} /$ $\mathrm{min} / \mathrm{mg}$, respectively, which was 2- to 4-fold higher than 


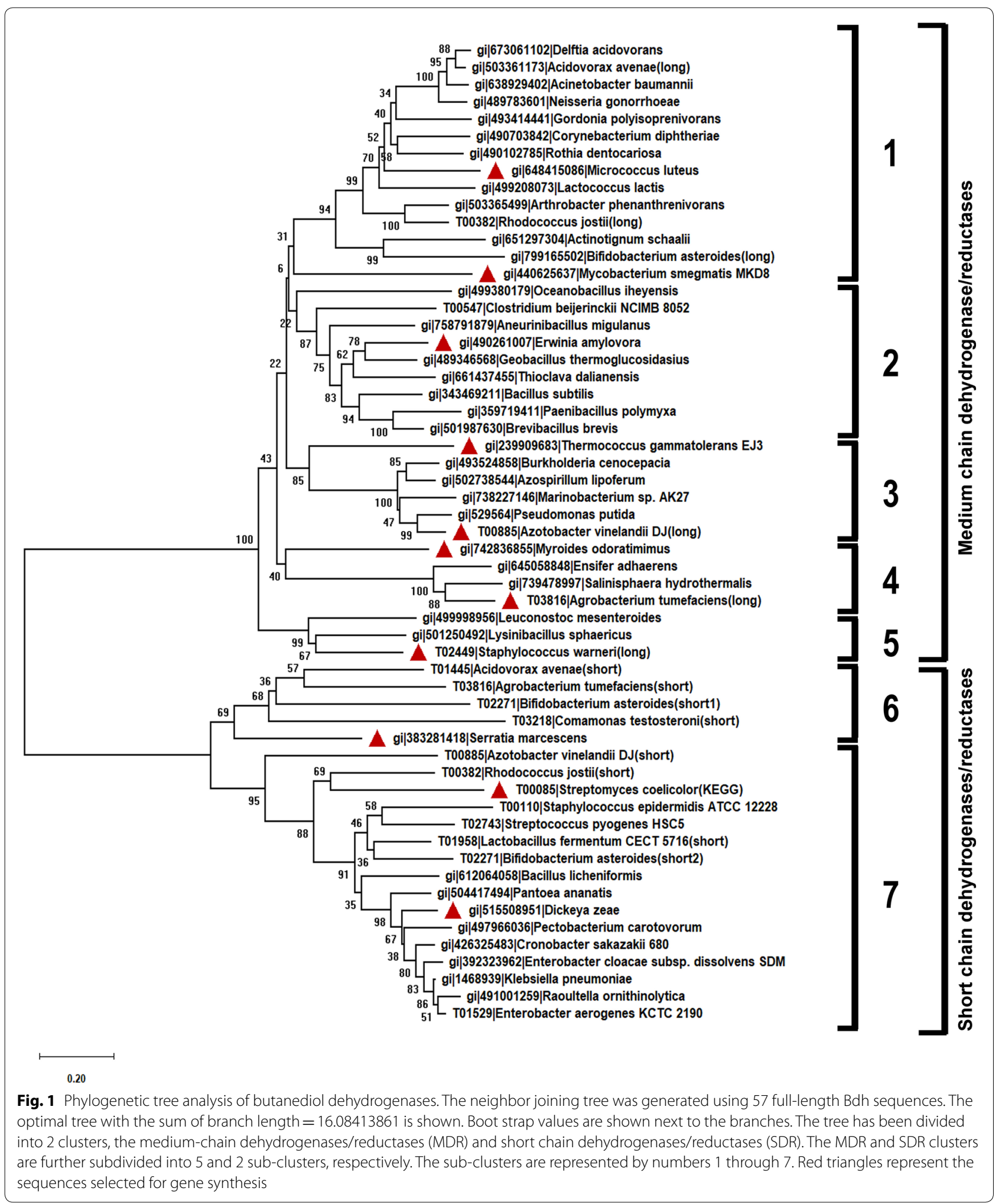


Table 1 Enzyme activity of 2,3-butanediol dehydrogenase enzymes expressed in Z. mobilis strain 9C

\begin{tabular}{|c|c|c|c|c|c|c|c|}
\hline Sample \# & $\begin{array}{l}\text { Origin of BDH } \\
\text { enzyme }\end{array}$ & $\begin{array}{l}\text { Activity } \\
\text { of the crude } \\
\text { extracts ( } \mu \mathrm{mol} / \\
\mathrm{min} / \mathrm{mg} \text { ) }\end{array}$ & $\begin{array}{l}\text { Average activity } \\
\text { of the crude } \\
\text { extracts ( } \mu \mathrm{mol} / \\
\mathrm{min} / \mathrm{mg} \text { ) }\end{array}$ & Sample \# & $\begin{array}{l}\text { Origin } \\
\text { of BDH } \\
\text { enzyme }\end{array}$ & $\begin{array}{l}\text { Activity } \\
\text { of the crude } \\
\text { extracts ( } \mu \mathrm{mol} / \\
\mathrm{min} / \mathrm{mg} \text { ) }\end{array}$ & $\begin{array}{l}\text { Average activity } \\
\text { of the crude extracts } \\
(\mu \mathrm{mol} / \mathrm{min} / \mathrm{mg})\end{array}$ \\
\hline \multirow[t]{2}{*}{1} & Negative control & ND & ND & 30 & Sw1 & $1.13 \pm 0.18$ & $1.15 \pm 0.38$ \\
\hline & & & & 31 & Sw2 & $1.42 \pm 0.27$ & \\
\hline 2 & $\mathrm{Ec}$ & $1.79 \pm 0.53$ & $1.79 \pm 0.53$ & 32 & Sw3 & $0.68 \pm 0.13$ & \\
\hline 3 & Bs & $0.34 \pm 0.06$ & $0.34 \pm 0.06$ & 33 & Sw4 & $1.71 \pm 0.17$ & \\
\hline 4 & $\mathrm{LI}$ & $1.73 \pm 0.16$ & $1.73 \pm 0.16$ & 34 & Sw5 & $0.81 \pm 0.21$ & \\
\hline 5 & Dd1 & $1.03 \pm 0.18$ & $1.92 \pm 0.51$ & 35 & Ea1 & $1.22 \pm 0.11$ & $1.75 \pm 0.29$ \\
\hline 6 & $\mathrm{Dd} 2$ & $2.47 \pm 0.08$ & & 36 & Ea2 & $2.08 \pm 0.58$ & \\
\hline 7 & Dd3 & $1.85 \pm 0.39$ & & 37 & Ea3 & $1.75 \pm 0.10$ & \\
\hline 8 & Dd4 & $1.87 \pm 0.29$ & & 38 & Ea4 & $1.79 \pm 0.48$ & \\
\hline 9 & Dd5 & $2.41 \pm 0.27$ & & 39 & Ea5 & $1.94 \pm 0.13$ & \\
\hline 10 & Sc1 & $1.71 \pm 0.52$ & $1.27 \pm 0.29$ & 40 & Ml1 & $2.41 \pm 0.89$ & $2.87 \pm 0.75$ \\
\hline 11 & Sc2 & $1.26 \pm 0.48$ & & 41 & $\mathrm{Ml} 2$ & $3.09 \pm 0.51$ & \\
\hline 12 & $\mathrm{Sc} 3$ & $1.13 \pm 0.03$ & & 42 & $\mathrm{Ml3}$ & $2.49 \pm 0.27$ & \\
\hline 13 & Sc4 & $1.42 \pm 0.37$ & & 43 & $\mathrm{Ml} 4$ & $2.14 \pm 0.08$ & \\
\hline 14 & $\operatorname{Sc} 5$ & $0.84 \pm 0.05$ & & 44 & Ml5 & $4.26 \pm 0.56$ & \\
\hline 15 & Sm1 & $6.48 \pm 0.97$ & $8.89 \pm 1.43$ & 45 & Mo1 & $1.40 \pm 0.26$ & $1.44 \pm 0.29$ \\
\hline 16 & $\mathrm{Sm} 2$ & $10.95 \pm 1.22$ & & 46 & $\mathrm{Mo} 2$ & $1.96 \pm 0.18$ & \\
\hline 17 & Sm3 & $9.27 \pm 1.21$ & & 47 & Mo3 & $1.48 \pm 0.24$ & \\
\hline 18 & Sm4 & $9.10 \pm 1.40$ & & 48 & Mo4 & $1.07 \pm 0.47$ & \\
\hline 19 & Sm5 & $8.67 \pm 0.92$ & & 49 & Mo5 & $1.30 \pm 0.38$ & \\
\hline 20 & At1 & $1.18 \pm 0.37$ & $1.15 \pm 0.59$ & 50 & Ms1 & $1.34 \pm 0.38$ & $1.27 \pm 0.24$ \\
\hline 21 & At2 & $1.18 \pm 0.27$ & & 51 & Ms2 & $1.22 \pm 0.29$ & \\
\hline 22 & At3 & $0.52 \pm 0.11$ & & 52 & Ms3 & $1.63 \pm 0.29$ & \\
\hline 23 & At4 & $2.22 \pm 0.15$ & & 53 & Ms4 & $0.87 \pm 0.33$ & \\
\hline 24 & At5 & $0.68 \pm 0.29$ & & 54 & Ms5 & $1.30 \pm 0.20$ & \\
\hline 25 & Av1 & $1.24 \pm 0.12$ & $1.30 \pm 0.35$ & 55 & $\operatorname{Tg} 1$ & $1.09 \pm 0.29$ & $1.13 \pm 0.39$ \\
\hline 26 & Av2 & $1.92 \pm 0.11$ & & 56 & $\operatorname{Tg} 2$ & $0.71 \pm 0.19$ & \\
\hline 27 & Av3 & $1.40 \pm 0.45$ & & 57 & $\operatorname{Tg} 3$ & $1.87 \pm 0.47$ & \\
\hline 28 & Av4 & $0.91 \pm 0.67$ & & 58 & $\operatorname{Tg} 4$ & $0.90 \pm 0.30$ & \\
\hline 29 & Av5 & $1.05 \pm 0.38$ & & 59 & $\operatorname{Tg} 5$ & $1.12 \pm 0.06$ & \\
\hline
\end{tabular}

Bdh activity assays were performed on whole cell extracts obtained from transformant cultures ( $\mu \mathrm{mol} / \mathrm{min}$ per mg crude extract). Each row represents activity assays performed in technical triplicates for every transformant. Five independent transformants were tested for each gene. Therefore, average specific activity has been calculated from $3 \times 5=15$ data points

Ec, E. cloacae; Bs, Bacillus subtilis; LI, Lactococcus lactis; Dd, Dickeya dadantii; Sc, Streptomyces coelicolor; Sm, Serratia marcescens; At, Agrobacterium tumefaciens; Av, Azotobacter vinelandii; Sw, Staphylococcus warneri; Ea, Erwinia amylovora; Ml, Micrococcus luteus; Mo, Myroides odoratimimus; Ms, Mycobacterium smegmatis; Tg, Thermococcus gammatolerans

the control strains. Based on the activity analysis, we selected S. marcescens Bdh (SmBdh) as the candidate enzyme for structural characterization. We also carried out SDS-PAGE analysis to determine expression of individual Bdh protein produced by these transformants. Interestingly, only some of the $b d h$ gene transformants showed unique bands at the expected molecular weight based on Coomassie staining (Additional file 3), suggesting different expression levels of the heterologous Bdh proteins. It is likely that some of these heterologous enzymes were not expressed to detectable levels, which may have been a factor in their poor activity levels. Nevertheless, for the purpose of screening, we used their crude extract activities as the standard to determine the best-expressing and active enzyme.

\section{Crystal structure of SmBdh along with its bound cofactor and substrate molecules}

Expression of a high-performing BDH enzyme in $Z$. mobilis is critical for 2,3-BDO production in this industrially relevant ethanol producer. Although the structural analysis of $S m B d h$ was not the primary intent of this 


\section{(See figure on next page.)}

Fig. 2 SmBdh functional complex and key structural features. a SmBdh tetramer. Protein chains $A, B, A^{\text {symm }}$ and $B^{\text {symm }}$ are shown in cartoon representation and colored grey, yellow, green and cyan, respectively. NAD ${ }^{+}, A D P$ and acetoin molecules are shown in sticks representation. $\mathrm{N}$ - and C-termini of the protein chains are marked. b'Open' and 'closed' conformations of SmBdh superimposed. Protein chains are shown in cartoon representation and colored grey except for the loop 180-203 containing helices a6 and a7.'Open' conformation of the loop 180-203 is colored purple and 'closed' conformation is colored green. Secondary structure elements are labeled. NAD ${ }^{+}$and acetoin molecules bound in 'closed' conformation are shown in sticks representation. Positions of Ca atoms of Ala93 and Trp192 are shown by arrows. c Zoom-in view of NAD + interaction with the 'closed' conformation of SmBdh. Side chains of Thr186, Met188, and Thr189 are shown in sticks representation. H-bonds formed upon $\mathrm{NAD}^{+}$binding are shown as yellow dashed lines

study, considering that this enzyme turned out to be the best expressed and most active enzyme in this organism, it was therefore deemed important to determine the reasons behind the improved functionality of this enzyme. The Z. mobilis expressed WT SmBdh crystallized in the space group $\mathrm{P}_{3}{ }_{2} 2$ with two protein molecules per asymmetric unit that could be superimposed with r.m.s.d. of $0.271 \AA$ over 1379 atoms. Two molecules found in the asymmetric unit form a tetramer (dimer of dimers) with a symmetry-related dimer (Fig. 2a) with extensive interface surfaces (Table 2, [35]). The tetrameric arrangement is common to the proteins belonging to the SDR superfamily. SmBdh was shown to be a tetramer in solution by Native PAGE [36]. The main difference between the two molecules in the asymmetric unit is that molecule A is found in 'closed' conformation (that could be best described by $\sim 10 \AA$ distance between $C \alpha$-atoms of residues Ala93 and Trp192) and molecule B is found in 'open' conformation (the same distance is $\sim 14 \AA$ ) (Additional file 4, Fig. $2 b$ and c). Upon examination of the electron density maps, we were able to locate $\mathrm{NAD}^{+}$cofactor molecule and acetoin molecules in protein molecule A ('closed' conformation Fig. 3a), while in molecule B ('open' conformation) the corresponding space is occupied by only adenine diphosphate (Fig. 3b).

The transition from the 'open' conformation into the 'closed' seems to be coincidental with $\mathrm{NAD}^{+}$binding and includes the shift of the loop 183-203, containing two helices, $\alpha 6$ and $\alpha 7$ (Fig. $2 b$, c). In the process, the short helix $\alpha 6$ is unfolded, but this is compensated by the hydrogen bonds formed between the $\mathrm{NAD}^{+}$and Thr186OY and between the main chain carbonyl of Val184 and Thr189OY (Figs. 2c, 3). Additional stabilization is likely provided by the hydrophobic interaction between Met188 side chain and nicotinamide ring (Fig. 2c). Interactions between protein and $\mathrm{NAD}^{+}$are shown in Fig. 3c.

WT SmBdh contains acetoin in the substrate-binding pocket of the 'closed' molecule A. Crystallization conditions included $\mathrm{NAD}^{+}$and acetoin, and more acetoin was used for cryoprotection. Omit electron density maps showed three bulges at the C3 atom (Fig. 4a). When only (3R)-acetoin molecule was modeled, a positive peak at the difference map showed up (Fig. 4b). We interpreted this as both (3R)- and (3S)-acetoin molecules bound in the pocket since commercially available acetoin is a racemic mixture and no other small molecules (like ethylene glycol) were added during crystallization or as a cryoprotectant. Out of three "bulges", only one should be modeled as a methyl group since its surrounding is hydrophobic (side chains of Leu183, Trp192, Phe200, and $\mathrm{Thr} 189 \mathrm{C} \gamma$ ) and no possible hydrogen bond donors or acceptors are available. Thus, this bulge was modeled as $\mathrm{C} 4$ atom of both (3R)-acetoin and (3S)-acetoin. Two other bulges, in contrast, have hydrogen bond partners

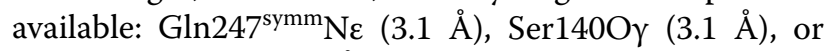
a water molecule $(2.7 \AA)$ for $(3 \mathrm{R})$-acetoin $\mathrm{O} 3$ atom, and $\operatorname{Gln} 247^{\text {symm }} \mathrm{O} \varepsilon(3.0 \AA)$ or Ser138 Oy (3.2 $⿱$ ) for (3S)-acetoin $\mathrm{O} 3$ atom.

\section{SmBdh belongs to the SDR superfamily of enzymes}

$S m B d h$ exhibits the typical single domain short-chain dehydrogenase/reductase (SDR) architecture. A monomer displays a dinucleotide-binding Rossmann fold that includes seven-stranded parallel $\beta$-sheet $(\beta 3-\beta 2-\beta 1-\beta 4-$ $\beta 5-\beta 6-\beta 7)$ flanked by three $\alpha$-helices $(\alpha 2, \alpha 1$, and $\alpha 8)$ on one side and three $\alpha$-helices $(\alpha 3, \alpha 4$, and $\alpha 5)$ on another. There is an additional small lobe on top of a core structure, formed by two short helices, $\alpha 6$ and $\alpha 7$, creating a deep cleft in which the cofactor is bound, and where the active site is located (Figs. 2 and 3). It should be noted that $S m B d h$ has been shown to be an NADH dependent dehydrogenase enzyme [18]. Two $\alpha$-turns ( $\alpha \mathrm{t} 1$ and $\alpha \mathrm{t} 2$ ) can also be recognized in this structure.

PDBeFold [37] search returned over 3000 molecules with Z-score between 6 (usually considered to be the lower threshold for likeliness) and 16.6, and sequence identity up to $37 \%$. Top matching structure could be superimposed over $S m B d h$ with r.m.s.d. of $1.03 \AA$ over $239 \mathrm{C} \alpha$-atoms (FabG from Bacillus sp., PDB ID 4NBU). While SDR superfamily is vast and includes enzymes active towards various substrates, there are several reported Bdh structures, namely from Burkholderia cenocepacea (BcBdh, PDB ID 4WEO), Burkholderia xenovorans (BxBdh, PDB ID 5JY1), C. glutamicum (PDB ID 3A28), Gluconobacter oxydans (GoBdh, PDB 


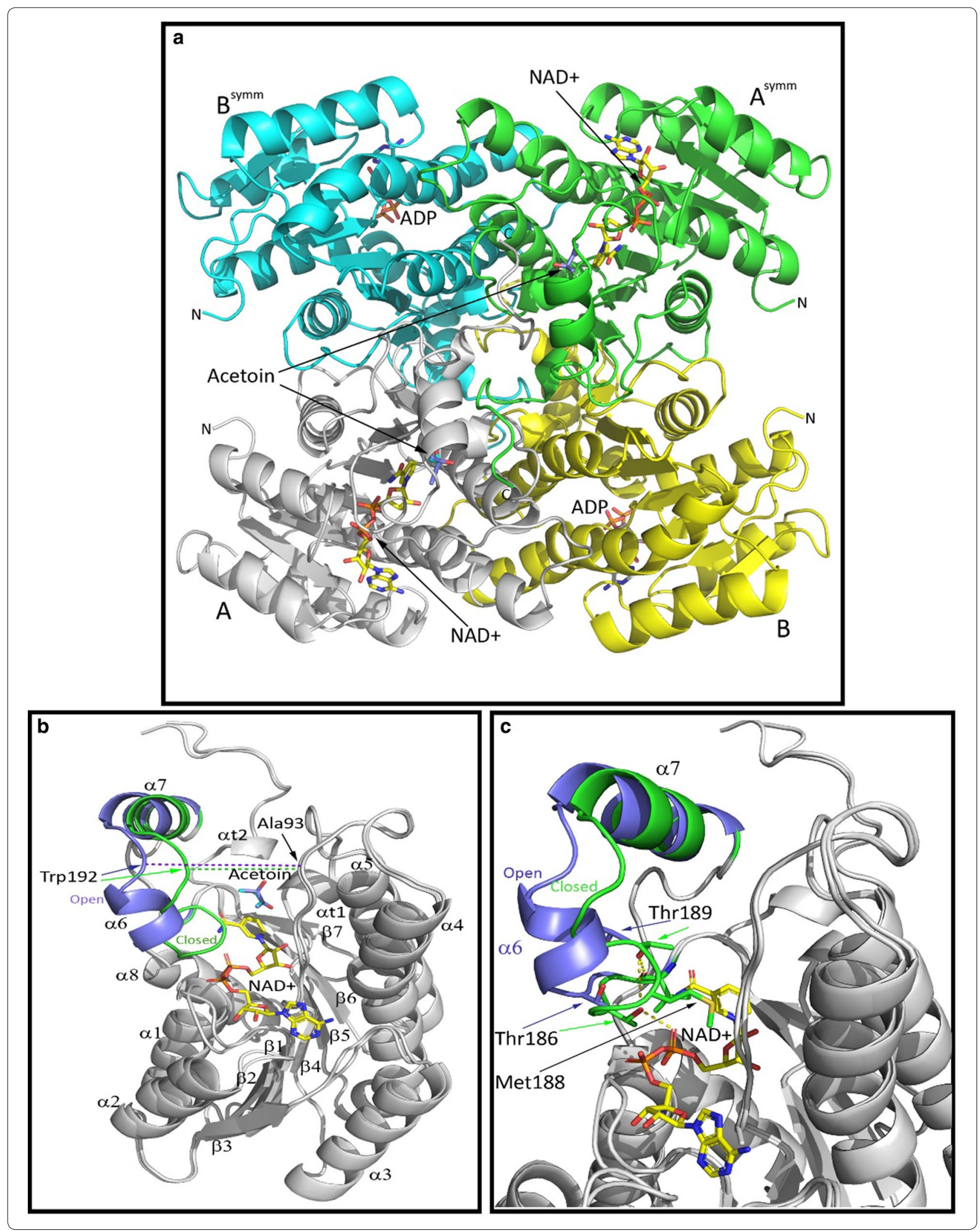


Table 2 Buried area of the protein-protein interfaces in the WT SmBDH tetramer

\begin{tabular}{llll}
\hline Assembly & Surface area, $\AA^{\mathbf{2}}$ & Buried area, $\AA^{\mathbf{2}}$ & Buried area, \% \\
\hline$A B A^{\text {symm }} B^{\text {symm }}$ & 31,520 & 16,820 & 53.4 \\
$A B^{\text {symm }}$ & 21,020 & 3140 & 14.9 \\
$A B$ & 21,530 & 2640 & 12.3 \\
$A A^{\text {symm }}$ & 21,150 & 2830 & 13.4 \\
$B B^{\text {symm }}$ & 21,940 & 2410 & 11.0 \\
$A$ & 11,992 & & \\
$B$ & 12,174 & & \\
\hline
\end{tabular}

ID 3WTC), and K. pneumoniae (KpBdh, PDB ID 1GEG) that are available in the PDB database. All mentioned enzymes are S-acting or S-installing, introducing $2 \mathrm{~S}$ chiral center in the acetoin molecule. However, only two enzymes are well characterized with regard to the substrate chiral specificity: Bdh from $K$. pneumoniae $(K p B d h)$ is (3R)-acetoin dependent [30] and Bdh from $C$. glutamicum (CgBdh) is (3S)-acetoin dependent [31]. An explanation for the chiral substrate recognition based on the spatial organization of the substrate-binding pocket has been presented before [31].

\section{Key differences in the $S m B d h$ structure lead to improved positioning of acetoin in the active site of the enzyme}

Placement of acetoin molecule inside the active site is key to the efficient conversion of this substrate to 2,3-BDO. To determine the structural characteristics that confers this property to the $S m B d h$ enzyme, we compared this protein with similar Bdhs from other organisms. Based on our assessment, the strategic placement of the hydrophobic cluster on the $\alpha \mathrm{t} 1$ side of the acetoin binding site (Ile142, Phe148, Leu151) and possible hydrogen bond partner on the $\alpha 6$ side of the acetoin binding site (Trp192) would be preferential for (3S)-acetoin binding in $C g B d h$ (Figs. 2b and 5a). The opposite arrangement: hydrophobic cluster on the $\alpha 6$ side of the acetoin binding site (Ile184, Trp190, Ile193, Phe212) and possible hydrogen bond partner(s) on the $\alpha$ t1 side (Ser139, Gln140) would be preferential for (3R)-acetoin binding in $K p$ Bdh (Figs. $2 \mathrm{~b}$ and $5 \mathrm{~b}$ ). We also analyzed the substrate binding sites of other Bdh enzymes such as those from $G o B d h, B c B d h$, and $B x B d h$. Analyzing substrate binding sites in these three Bdh enzymes suggested that GoBdh and $B c B d h$ are likely (3S)-acetoin dependent, whereas $B x \mathrm{Bdh}$ is likely (3R)-acetoin dependent. For simplicity, we used $K p B d h$ and $C g B d h$ as reference structures to compare the acetoin binding site of $S m B d h$. SmBdh stands out when compared to these two protein structures. At a first glance, it looks similar to the $K p B d h-a$ hydrophobic cluster made of Leu183, Thr189Cy, Trp192, and Phe200 located on the $\alpha 6$ side of the groove is well suited for interaction with the $\mathrm{C} 4$ atom of the acetoin molecule (Figs. 5b and c). However, Gln140 of the $K p B d h$ is replaced with Val139 in $S m B d h$. In this protein, another glutamine side chain makes up for that difference (i.e., Gln $247^{\text {symm }}$ from a symmetry-related molecule). Other differences then start to accumulate. Whereas in $C g B d h$ and $K p$ Bdh the number of partners for possible $\mathrm{H}$-bonds stabilizing $\mathrm{O} 3$ atom of acetoin is very limited-one $(\operatorname{Trp} 192 \mathrm{Ne})$ and possibly two $(\mathrm{Gln} 140 \mathrm{Ne}$ and Ser139Oy), respectively, the acetoin binding site in SmBdh has a vast H-bond network better suited to stabilize both acetoin enantiomers. Specifically, 1: Leu151/149 of $C g \mathrm{Bdh} / \mathrm{Kp} \mathrm{Bdh}$, respectively, is replaced with Ala148 in $S m B d h$ creating a void where a water molecule W71 is now located (Fig. 5c). This water molecule is held in place by $\mathrm{N} \varepsilon$ of His 91 that replaced Ala $92 / 90$ of $C g B d h / K p B d h$, respectively, and $\mathrm{O} \delta$ of Asp145. This water molecule is placed within $2.7 \AA$ from O3 atom of (3R)-acetoin molecule in SmBdh. 2: Ala143/141 of $C g B d h / K p$ Bdh, respectively, is replaced with Ser140 in SmBdh and Ser140OY is within $3.1 \AA$ from the $\mathrm{O} 3$ atom of (3R)-acetoin. $\mathrm{N} \varepsilon$ of the $\mathrm{Gln} 247^{\text {symm }}$ is situated $3.1 \AA$ away from the O3 atom of (3R)-acetoin (Fig. 5c). 3: For the (3S)-acetoin, its O3 atom is located $2.8 \AA$ away from O $\varepsilon$ of the Gln $247^{\text {symm }}$ and $3.2 \AA$ away from Ser138OY (Fig. 5c). We can suggest that significant improvements in supporting the hydrogen bond network in the active site of $S m B d h$, in comparison to the other known Bdhs, contributes to more precise positioning of acetoin molecule in the active site and probably better stabilization of the reaction intermediate which could in turn lead to higher turnover of the substrate.

\section{Substrate promiscuity of the SmBdh enzyme}

Most of the characterized Bdh enzymes show strong preference to either (3S)- or (3R)-acetoin as a substrate $[24,33,38,39]$. SmBdh was reported to be able to reduce both (3R)- and (3S)-acetoin to 2,3-BDO, although (3R)acetoin was more readily converted than (3S)-acetoin [18]. On the other hand, $S m B d h$ was able to oxidize meso-2,3-BDO and (2S,3S)-BDO, while oxidation of $(2 \mathrm{R}, 3 \mathrm{R})-\mathrm{BDO}$ was not detectable. Moreover, its activity towards $(2 \mathrm{~S}, 3 \mathrm{~S})$ - $\mathrm{BDO}$ was only $11 \%$ of that towards meso-2,3-BDO [18]. This observation was similar to that reported by Médici et al. where (3R)-acetoin was found to be the preferred substrate in the racemic mixture of acetoin. Fifteen percent of the (3S)-acetoin remained unconverted after $24 \mathrm{~h}$ in their study [36]. Indeed, in our crystal structure we were able to locate both acetoin enantiomers in the active site. Whereas the positions of all acetoin atoms, with the exception of O3, superimpose 

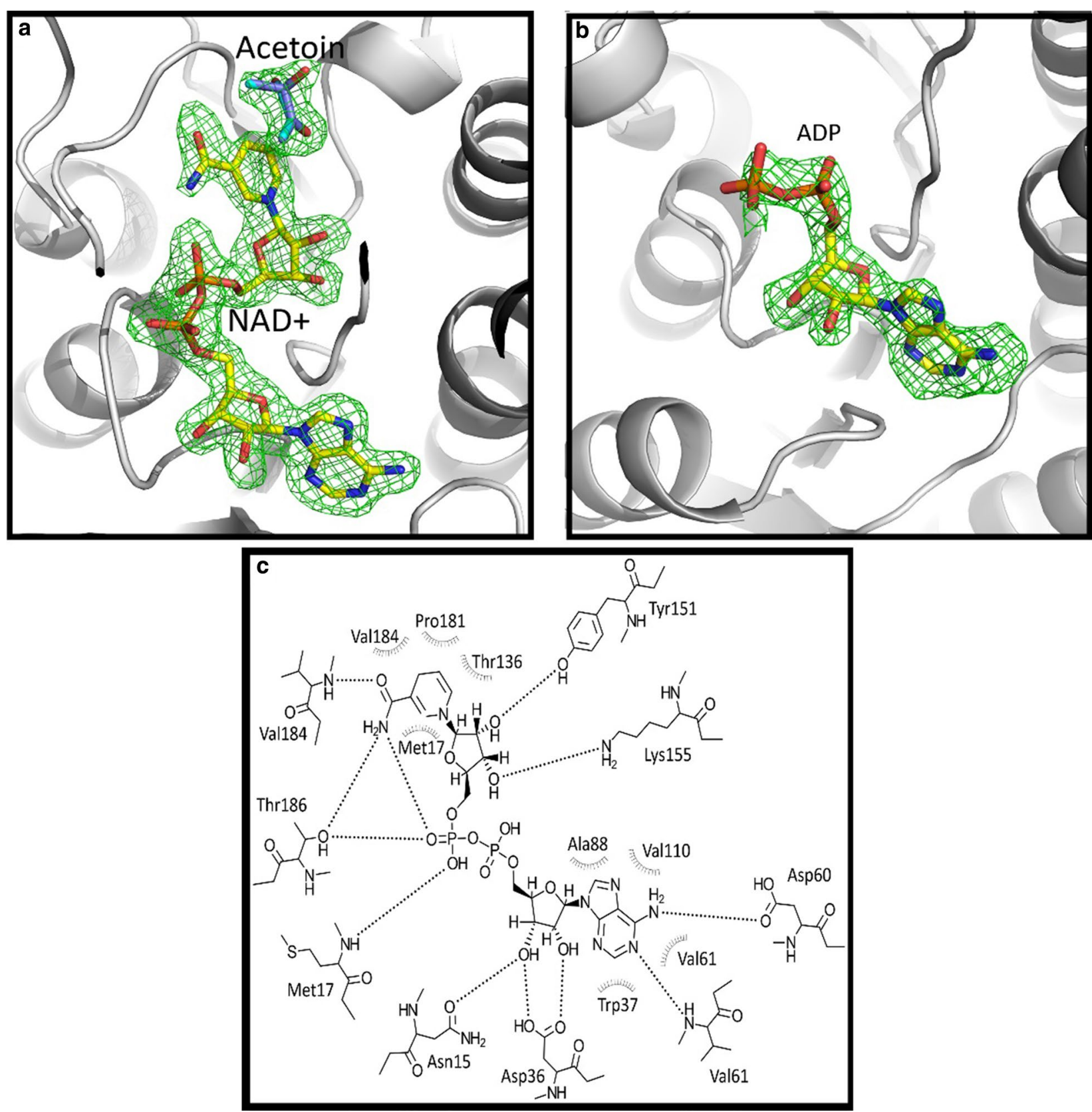

Fig. 3 Substrate and cofactor interactions within SmBdh molecule. a Omit Fo-Fc electron density map (calculated after NAD ${ }^{+}$and acetoin molecules removed from the model) shown at $3 \sigma$ level for the NAD ${ }^{+}$and acetoin molecules found in the 'closed' conformation of the WT SmBdh. b Omit Fo-Fc electron density map (calculated after ADP molecule was removed from the model) shown at $3 \sigma$ level for the ADP molecule found in the 'closed' conformation of the WT SmBdh. c NAD ${ }^{+}$interactions with the 'closed' conformation of the WT SmBdh

quite well; the $\mathrm{O} 3$ atoms of (3S)- and (3R)-acetoin molecules are involved in hydrogen bonds with different surrounding residues (Figs. 4, 5c). This finding supports the idea of productive binding of both acetoin enantiomers in the active site. Still, (3S)- and (3R)-acetoin molecules are not treated equally by the $S m B d h$. We suggest that the differences in the hydrogen bond networks of the (3S)-acetoin and (3R)-acetoin can explain our findings. Specifically, the $\mathrm{O} 3$ atom of the (3S)-acetoin is only involved in one hydrogen bond with Gln $247^{\text {symm }} \mathrm{O} \varepsilon$ (or $\mathrm{N} \varepsilon$ if the side chain is flipped). While Ser138Oy is located only $3.2 \AA$ away from (3S)-acetoin O3, the geometry is not favorable for the $\mathrm{H}$-bond formation. In contrast, $\mathrm{O} 3$ atom of the (3R)-acetoin has three possible partners for 

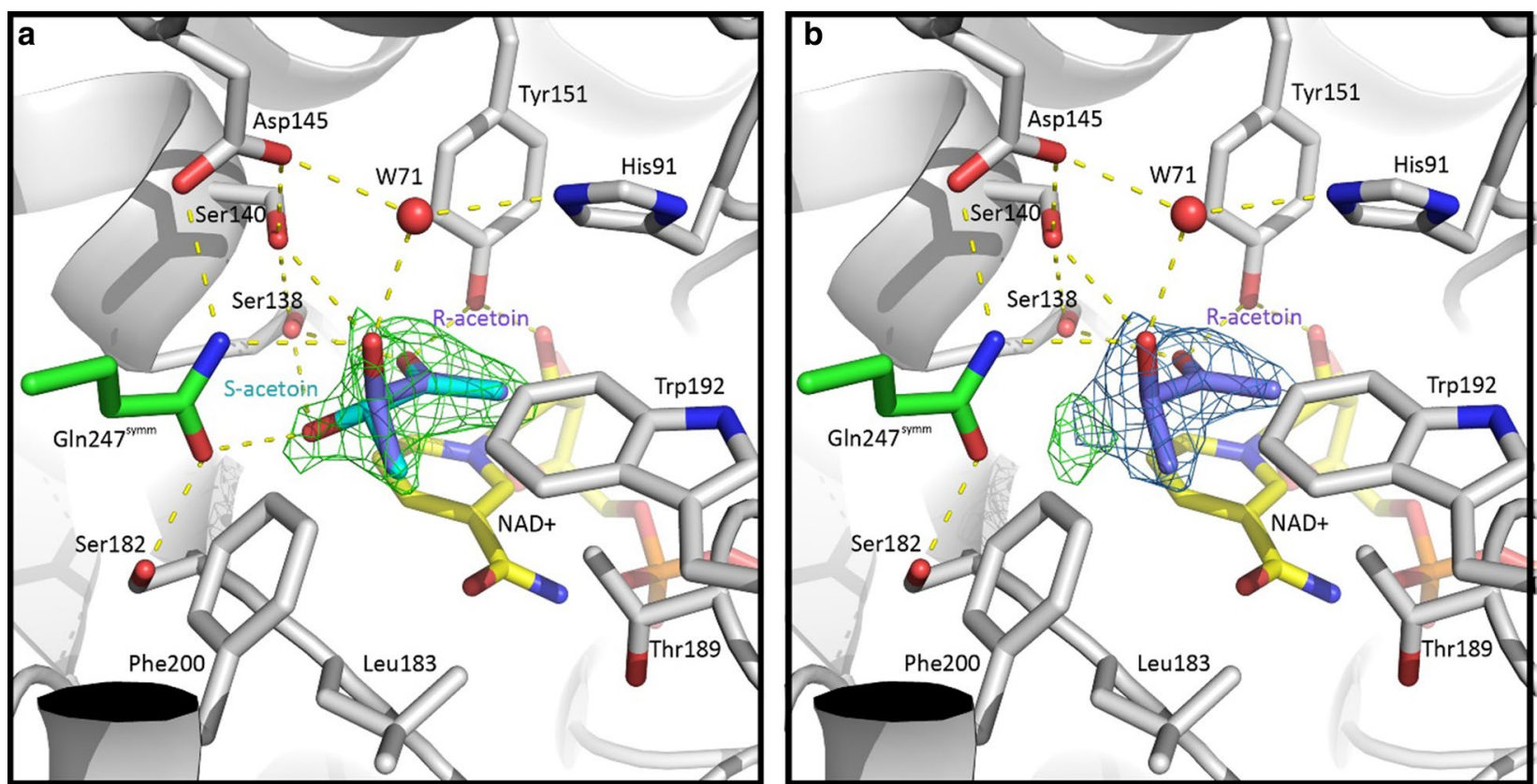

Fig. 4 Placement of acetoin molecules in the active site of SmBdh and its intramolecular interactions. a Placement of R-and S-acetoin molecules in the active site of the WT SmBDH. NAD + (yellow carbons), R- and S-acetoin molecules (purple and cyan carbons), and side chains of surrounding residues (grey carbons) including GIn247 from the symmetry-related molecule (green carbons) are shown in sticks representation. Hydrogen bonds are depicted as yellow dashed lines. Omit Fo-Fc electron density map at $3 \sigma$ level is shown as a green mesh over acetoin molecules. $\mathbf{b}$ When only R-acetoin is modeled in the active site of the WT SmBDH, a strong peak in the Fo-Fc map appears after refinement (shown as a green mesh at $3 \sigma$ level) indicating incomplete interpretation of the electron density maps. 2Fo-Fc map contoured at $1 \sigma$ level is also shown
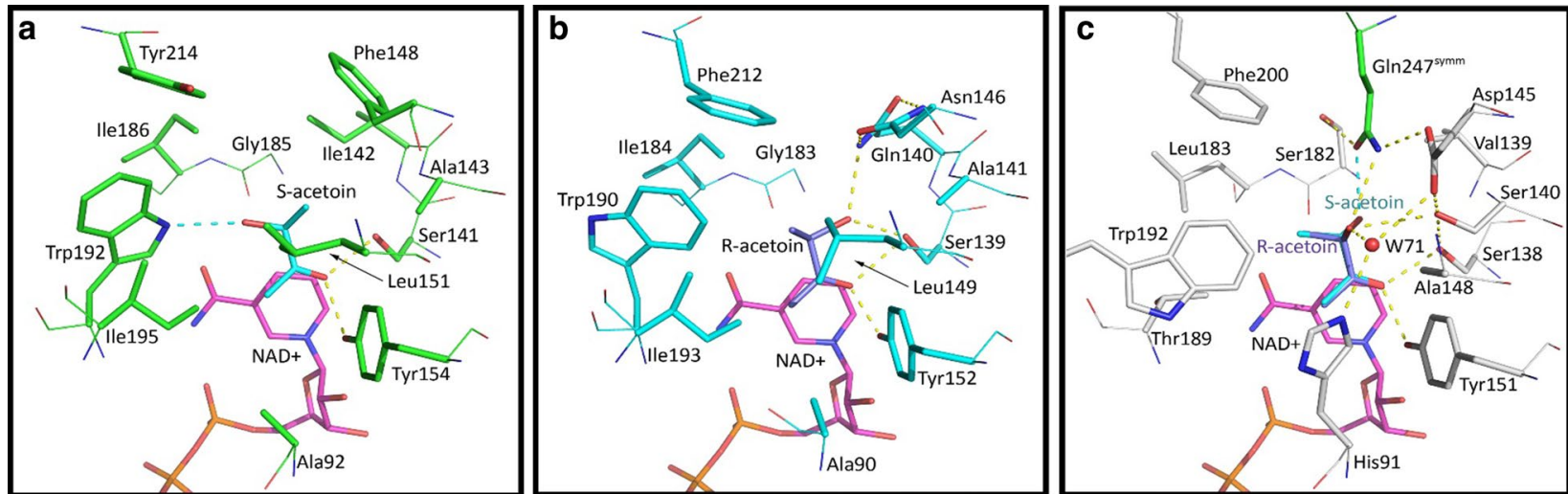

Fig. 5 Comparison of the acetoin binding sites of S-acting Bdh enzymes. a CgBdh; b KpBdh, and c SmBdh. Carbon backbone are represented in green for $\mathrm{CgBdh}$, cyan for $\mathrm{KpBdh}$ and grey for $\mathrm{SmBdh}$. Main chain atoms of the amino acid residues involved in the substrate binding are shown in lines and side chains are shown in sticks. $\mathrm{NAD}^{+}$substrate is shown in sticks with magenta carbons. (3S)-acetoin in CgBdh is represented in cyan backbone and (3R)-acetoin in KpBdh is represented in purple backbone, are modeled following acetoin binging in SmBdh using C1, C2, C3 and O2 atoms of the acetoin molecules in SmBdh as anchors. Available hydrogen bonds are depicted as yellow dashed lines. Hydrogen bonds specific for (3S)-acetoin $\mathrm{O} 3$ atom are depicted as cyan dashed lines (panels $\mathbf{a}$ and $\mathbf{c}$ ). W71 indicates a water molecule

H-bond formation: water molecule W71 (2.7 $\mathrm{A}), \mathrm{N} \varepsilon$ of the $\operatorname{Gln} 247^{\text {symm }}(3.1 \AA)$, and Ser140OY (3.1 $)$ ). It is possible that the "more complex" H-bond network provides better stabilization of the reaction intermediate, which could in turn lead to higher turnover of the (3R)-acetoin in comparison to (3S)-acetoin. 


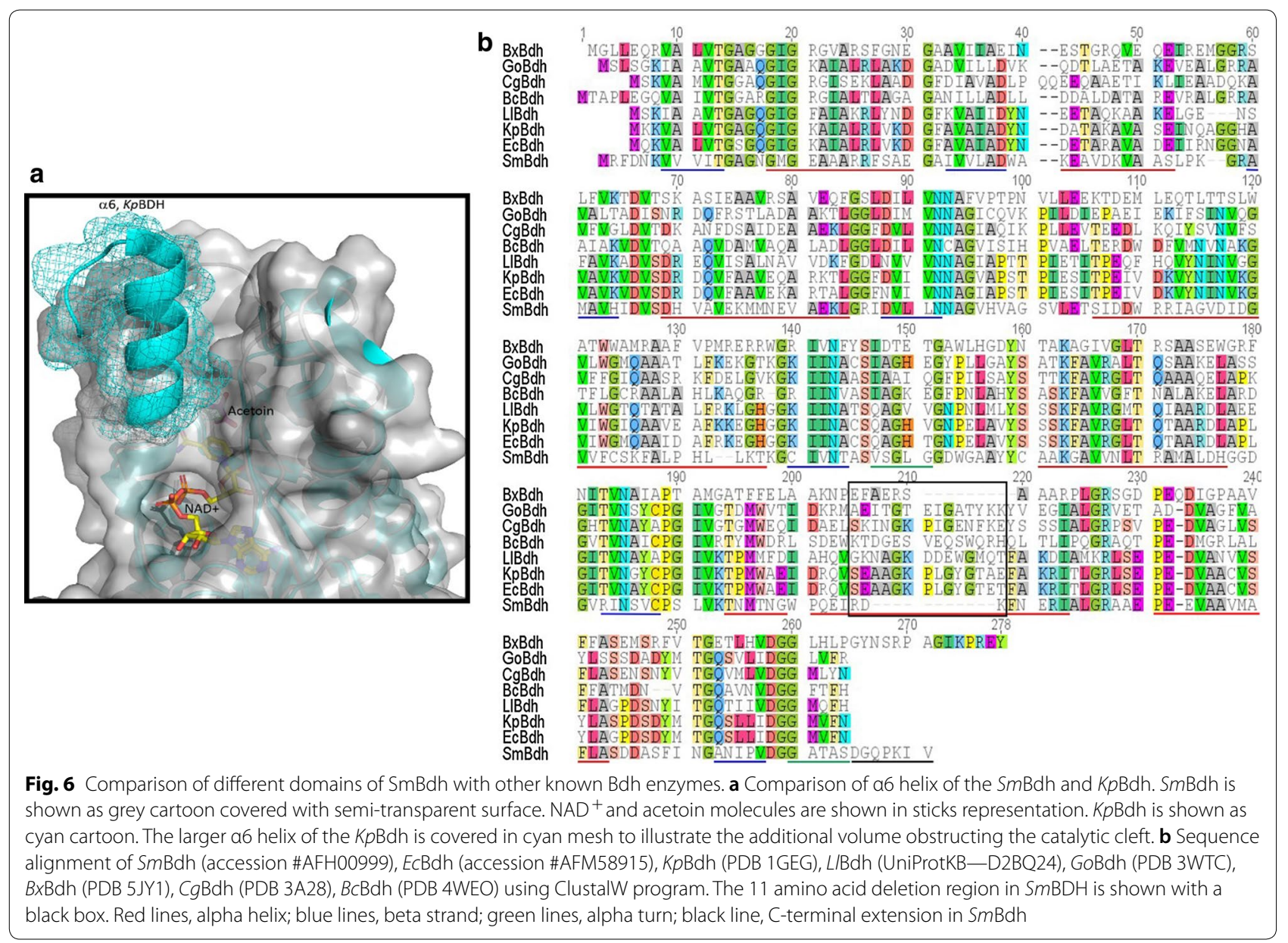

\section{Shorter $a 6$ helix results in possible improvement} in ingress/egress of the cofactor and the substrate/product Although the general fold of the $S m$ Bdh monomer is very common, we identified several features that are unique to this enzyme. Comparing $S m B d h$ structure with other Bdh structures we found no coexistence of both 'open' and 'closed' conformations in other Bdhs: the active sites in all molecules in the tetramer are either equally populated in the liganded structures or not populated at all. In $S m B d h$, two molecules of the tetramer are found in an 'open' conformation with substrate binding sites empty and two molecules in 'closed' conformation with populated substrate binding sites. This observation points to the possibility of a concerted 'tug-of-war' motion in the $S m$ Bdh tetramer, where closure of active sites of two diagonally opposite molecules leads to expansion of the active sites of the other two molecules for faster replenishment with the cofactor and the substrate (Fig. 2a).

Comparison between $S m B d h$ and Bdhs with known structures shows a shortened $\alpha 6$ helix in $S m B d h$ (also known as FG1 in SDR structure description) (Fig. 6). The $\alpha 6$ helix is six residues long in $S m B d h, 10$ residues long in $B \times B d h$ and 15 residues long in $K p B d h, C g B d h$, and GoBdh. The shortened $\alpha 6$ helix provides wider opening of the catalytic cleft thus improving access to the NADH/ $\mathrm{NAD}+$ and acetoin/2,3-BDO binding sites and easing ingress/egress of the cofactor and substrate/product.

\section{Substrate-binding pocket is formed by two protein molecules in SmBdh, unlike the others}

One of the most interesting and exclusive features of $S m B d h$ is the organization of the active site. We found that the substrate-binding pocket is formed by two protein molecules, not a single peptide as found in all other reported Bdh enzymes. The C-terminus of molecule A protrudes into the groove between $\alpha 7$ helix and the $\alpha$-turn $\alpha$ t1 capping substrate-binding pocket of molecule $A^{\text {symm }}$ and vice versa (Fig. 2a). The side chain of Q247 ${ }^{\text {symm }}$ is involved in the substrate positioning forming a hydrogen bond with the $\mathrm{O} 3$ atom of the acetoin. (Fig. 5). In most SDRs the groove between $\alpha 7$ helix and $\alpha$-turn $\alpha \mathrm{t} 1$ is unobstructed and open to the solvent, but there are examples of active sites with the involvement of the second protein chain, for example: $17 \beta$ hydroxysteroid 

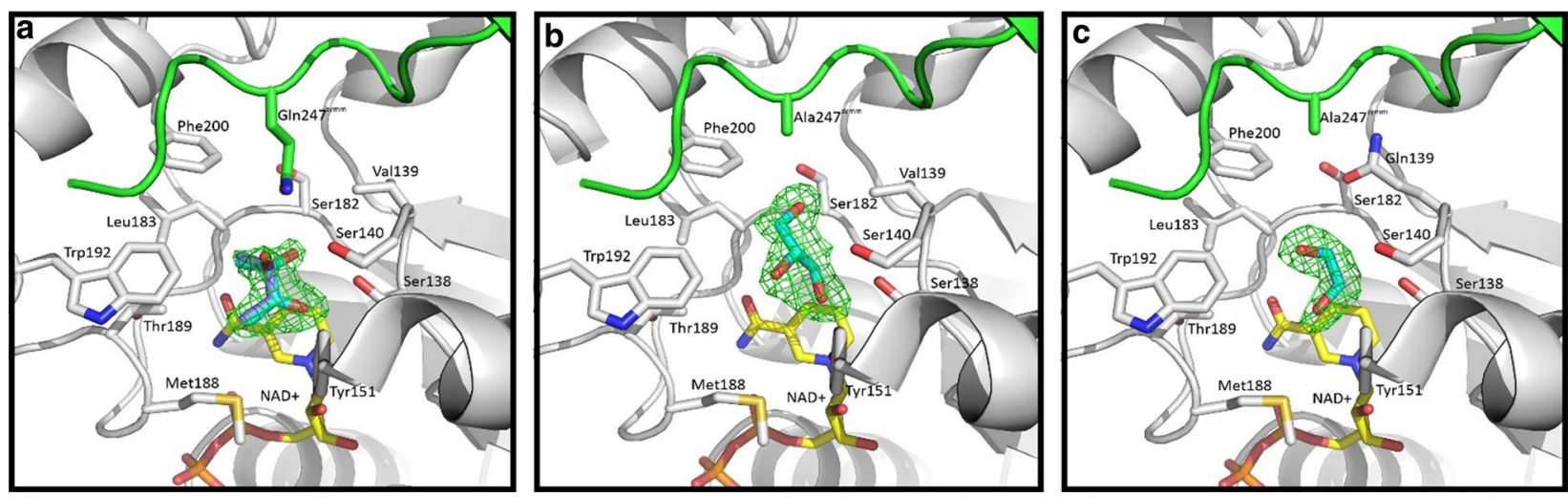

Fig. 7 Modeled structures of the active site of $S m B d h$ and its variants along with their substrates. a Omit Fo-Fc electron density map at $3 \sigma$ level is shown as a green mesh over acetoin molecules in the active site of the WT SmBdh. $\mathbf{b}$ Omit Fo-Fc electron density map at $3 \sigma$ level is shown as a green mesh over glycerol molecule in the active site of the Q247A SmBdh mutant. c Omit Fo-Fc electron density map at 30 level is shown as a green mesh over ethylene glycol molecule at the active site of the Q247A +V139Q SmBdh double mutant

dehydrogenase 14 from Homo sapiens (1yde, [40, 41]), alcohol dehydrogenase from Arthrobacter sp. TS-15 (6qhe, [42]), and glucose dehydrogenase 4 from Bacillus megaterium (3auu, [43]). Searching through the PDB, we could not find any other Bdh structure where the active site required the participation of a second protein molecule, so $S m B d h$ is the first Bdh with this feature. The only similar functional aspect of the involvement of $\mathrm{C}$-terminus in active site formation is found in the case of $B x \mathrm{Bdh}$, where it protrudes into the same protein molecule instead of a different protein molecule, as in $\mathrm{SmBdh}$.

There are several consequences of this substrate-binding pocket organization. First, $S m B d h$ would only be active as a tetramer because the active site is incomplete unless tetramerization is achieved. In other Bdh enzymes active sites are solely formed by a single protein molecule and the enzymatic activity in theory could occur in the monomeric or dimeric state. Second, the presence of the C-terminal portion of another protein molecule near the substrate-binding pocket creates a cap making the pocket much less accessible from the solvent compared to other Bdh enzymes. Third, higher specificity towards acetoin is another possible consequence as the substrate binding site is restricted in volume and cannot accept any larger substrate. This concept is in good agreement with the observation that $S m B d h$ prefers smaller substrates, such as vicinal diketones/diols that do not contain bulky groups [36]. Tighter and more specific binding of the acetoin molecule could be achieved due to an improved hydrogen bonding network (as explained in the section "Key differences in the $S m B d h$ structure lead to improved positioning of acetoin in the active site of the enzyme"); thereby improving reaction intermediate stabilization and ultimately enhancing catalytic efficiency of the SmBdh.

\section{Mutational studies of the SmBdh Gln247 plays a crucial role in SmBdh catalysis}

Based on structural evidence that we have obtained, Gln247 seems to play an important role in the hydrogen bonding-mediated stabilization of the substrate, as well as better positioning of the substrate in the substrate-binding pocket of the protein. This is important in the context of the overall catalytic ability of this protein; as well as proving to be one of the critical parameters that could make $S m B d h$ a better performing Bdh enzyme in comparison to its closely related homologs. In order to determine the importance of the Gln247 side chain for the catalysis, we developed two mutants of SmBdh: (1) Q247A where this side chain is removed, leaving alanine at position 247 and (2) the double mutant Q247 A + V139Q, where the missing glutamine side chain would be reinstated at the position 139 that is present in $K p$ Bdh (Fig. 7, Additional files 5 and 6). Whereas Q247A will disrupt the active site of the protein, Q247A + V139Q is expected to restore the active site via a compensatory mechanism resulting in the active site being established by a single protein chain without contribution from a symmetry-related molecule (i.e., from the C-terminus of the opposite molecule in the tetramer).

The SmBdh Q247A and the Q247A + V139Q mutants crystallized in the same space group $\left(\mathrm{P}_{3} 2_{1} 2\right)$ as the WT $S m$ Bdh repeating its protein chains arrangement. Two protein molecules per asymmetric unit could be superimposed with r.m.s.d. of $0.275 \AA$ over 1400 atoms (Q247A), and $0.263 \AA$ over 1368 atoms (Q247A + V139Q). As with the WT $S m B d h$, the primary difference between the two 
molecules in the asymmetric unit in the mutant structures was that molecule A was found in 'closed' conformation (that could be best described by $\sim 10 \AA$ distance between $\mathrm{C} \alpha$-atoms of residues Ala93 and Trp192) and molecule $B$ was found in 'open' conformation (the corresponding distance is $\sim 15 \AA$ ) (Additional file 4, Fig. 2). Upon examination of the electron density maps, we were able to locate $\mathrm{NAD}^{+}$cofactor molecule and a substrate in protein molecule A ('closed' conformation), whereas in molecule B ('open' conformation) the corresponding space is occupied by only adenine diphosphate (as in Q247A mutant) or remains unoccupied (as in Q247A + V139Q mutant) at all. The substrate binding site was found to be occupied by glycerol molecule in Q247A mutant and ethylene glycol in Q247A + V139Q mutant (Fig. 7).

In the Q247A mutant structure, a glycerol molecule was modeled at the substrate-binding pocket (Fig. 7b). Acetoin was present in the crystallization conditions, but our attempts to use additional acetoin for cryoprotection only led to crystal damage. Therefore, a $50 / 50 \mathrm{v} / \mathrm{v}$ mix of glycerol and ethylene glycol was used for cryoprotection. We postulate that the absence of the $G \ln 247^{\text {symm }}$ side chain led to an increase of the available space for the substrate and therefore the larger glycerol molecule could be bound. In the Q247A + V139Q double mutant structure, an ethylene glycol molecule was modeled at the substrate-binding pocket (Fig. 7c). As with the Q247A mutant, acetoin was present during crystallization, but raising its concentration was damaging to the crystals. A $50 / 50 \mathrm{v} / \mathrm{v}$ mix of glycerol and ethylene glycol was therefore used for cryoprotection. We suggest that the available space in the substrate binding site became reduced compared to the Q247A single mutant, thereby providing insufficient space for glycerol to fit. Instead, ethylene glycol which is comparable in size to acetoin could fit.

We further tested the activity of both these mutants using the NADH consumption assay to determine the effect of these mutations on the function of the protein. In comparison to the WT SmBdh, Q247A mutant showed a $\sim 90 \%$ loss in activity as predicted by the structure, whereas the double mutant Q247A+V139Q showed $300 \%$ improvement in activity in comparison to Q247A mutant (Fig. 8). Although the double mutant did not completely restore the loss of Gln247 activity, significant function was regained by introducing the V139Q mutation in this protein. It can thus be inferred that Gln247 is extremely important for the activity of the protein, which cannot be fully restored by a complementary mutation, such as V139Q. However, this is not a thorough analysis of complementation of the Q247A mutation and there could be other mutations that could help restore full functionality of the Q247A mutation.

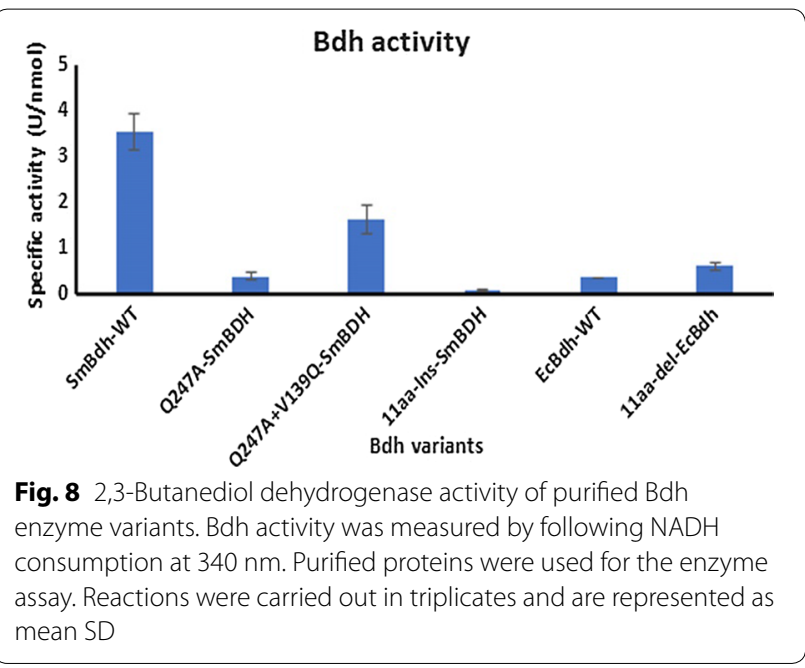

This analysis also highlights the importance of the C-terminal Gln247 from the opposite molecule in conferring full functionality.

\section{Extending the short a 6 helix of $S m B d h$ results in loss in activity}

Comparing the different Bdh enzymes, we found that most of the S-acting Bdh enzymes, such as $E c B d h$, $\mathrm{CgBdh}$, and $\mathrm{Kp} \mathrm{Bdh}$ have longer $\alpha 6$ helix structure (Fig. 6), whereas deletion of 11 amino acid residues in the $S m B d h$ leads to a shorter $\alpha 6$ helix along with a shorter linker between the $\alpha 6$ and $\alpha 7$ helices. Based on the activity analysis data (Table 1, Fig. 8), it was clear that $S m B d h$ is much more active than the control enzymes, which include EcBdh. Furthermore, structural analysis also suggested that the shortened $\alpha 6$ helix contributes to the improved ingress or egress of the substrate and/or the product molecules. This result prompted us to investigate the role of this important structural difference in $S m B d h$ with regard to enzyme performance. In order to support this hypothesis, we used two Bdh enzymes$S m B d h$ with short $\alpha 6$ helix and $E c B d h$ with long $\alpha 6$ helix. Sequence alignments with highlighted differences are shown in Fig. 6b. We designed two mutants: (1) 11aa-Ins$S m B d h$, where sequence fragment "RDK" was replaced with "SEAAGKPLGYGTET" to mimic longer $\alpha 6$ helix of $E c B d h$ and (2) 11aa-del-EcBdh, where the amino acid sequence "SEAAGKPLGYGTET" was replaced with "RDK" to mimic the corresponding shorter $\alpha 6$ helix of $S m B d h$. The residues flanking these regions in $E c B d h$ and $S m B d h$ showed acceptable homology, so we decided to keep the swap region as small as possible. Proteins were expressed in the $Z$. mobilis $9 \mathrm{C}$ strain, purified to homogeneity and subjected to activity analysis using the $\mathrm{NADH}$ consumption assay. As expected, activity of the 
11 aa-Ins-SmBdh was greatly reduced (down to $3 \%$ of the WT activity) with the insertion, whereas the activity of 11 aa-del-EcBdh increased by $~ 70 \%$ in comparison to WT EcBdh (Fig. 8), suggesting that the size of the $\alpha 6$ helix contributes to the unique activity of $S m B d h$ in comparison to the other S-acting Bdhs. Nevertheless, replacing the longer $\alpha 6$ helix in $E c B d h$ with the shorter helix from $S m B d h$ did not render $E c$ Bdh similar to $S m B d h$ in terms of its activity; we found that the activity of the 11aa-del$E c$ Bdh was only $17 \%$ of WT $S m B d h$ (Fig. 8). This clearly suggests that while the short $\alpha 6$ helix is important for the high activity of $S m B d h$, there are other structural features that this enzyme possesses that also contribute towards its superior performance.

\section{Conclusions}

Based on expression of 11 phylogenetically different Bdh enzymes, we have identified that the $S$. marcescens Bdh enzyme shows the highest activity when expressed in $Z$. mobilis. This enzyme has been classified as an S-acting Bdh based on production of meso-2,3-BDO and (2S,3S)BDO from a racemic mixture of acetoin. We have structurally characterized this enzyme and ascertained the distinct structural features that may be critical for its activity. Specifically: (1) this enzyme is organized as a tetramer with diagonally opposite protein molecules acting in tandem, such that one diagonally opposite pair is bound by the substrate in the closed conformation, with the other two protein molecules in the tetramer found ready to take up new substrate molecules in the open confirmation. This is the first instance of a pistontype function of a Bdh enzyme. (2) The active site of the $S m B d h$ enzyme is formed with the participation of the $G \ln 247$ of the opposite molecule from the tetramer, removal of this residue causes severe functional defects to the protein. A complementary mutation that introduces a glutamine partially restores the function of this protein. (3) SmBdh possesses improved hydrogen bond network resulting in better positioning of the substrate in its active site. (4) $S m B d h$ is able to bind to both (3S)and (3R)-acetoin productively and we were able to locate both substrate molecules in the active site of the crystal structure, thus providing the structural confirmation to the enzyme substrate promiscuity. (5) The presence of a shorter $\alpha 6$ helix provides a wider cleft for efficient entry and exit of the substrate and products, respectively, to $S m B d h$. We have experimentally verified this hypothesis by introducing residues from a low activity Bdh enzyme (i.e., $E c B d h$ ), which resulted in dramatic reduction in activity of this protein. (6) Finally, we have also demonstrated that deletion of residues that shortened the a6 helix of $E c B d h$ can result in dramatic increase in its activity $(\sim 70 \%)$, which could prove to be a game-changer when considering low-active Bdh enzymes for 2,3-BDO production. Overall, this work has identified a superior heterologous Bdh enzyme suitable for expression in $Z$. mobilis. Moreover, availability of a strain expressing this Bdh enzyme is expected to greatly alleviate one of the major bottlenecks involved in 2,3-BDO production by this organism. The next logical step would be to incorporate the $S m \mathrm{BDH}$ into a $Z$. mobilis strain carrying the other two BDO pathway genes, Als and Aldc. Our future work will involve testing the $S m B d h$ in combination with other Als and Aldc enzymes to identify the best combination of enzymes that would lead to improvement in 2,3BDO production.

\section{Materials and methods} Strain and growth conditions

Zymomonas mobilis strain 9C (ZM4 derivative strain with xylose-utilizing abilities) was revived from glycerol stocks and grown in rich medium (RM, $10 \mathrm{~g} / \mathrm{L}$ yeast extract, $2 \mathrm{~g} / \mathrm{L} \mathrm{KH}_{2} \mathrm{PO}_{4}$ ) containing 5\% glucose (RMG) at $30{ }^{\circ} \mathrm{C}$ under shaking conditions $(120 \mathrm{rpm})$. Spectinomycin at a concentration of $200 \mu \mathrm{g} / \mathrm{mL}$ was used to maintain transformant colonies.

\section{Phylogenetic analysis of Bdh}

Initially, 52 Bdh amino acid sequences were obtained from the NCBI database. These Bdh sequences represented one enzyme per genus under the assumption that Bdh enzymes within the same genus would have similar structures and functions. Two distinct sets of Bdh sequences were formed based on their sequence lengths. One set contained 350 aa, while the other contained $\sim 250$ aa. In genera containing both sequence types, both the sequences were selected. In the end, 57 Bdh sequences were used for phylogenetic analysis. Fulllength Bdh sequences were aligned using ClustalW, and phylogenetic analysis was carried out using the MEGA X software [44]. The unrooted evolutionary tree was generated using the neighbor joining method [45]. A bootstrap value of 1000 replications was used for the analysis [46]. All gaps and ambiguous positions were removed using the pairwise deletion option. The evolutionary distances were calculated using the Poisson correction method [47].

\section{Plasmid construction, transformation, and screening of transformants}

Eleven $b d h$ gene sequences were codon-optimized for expression in Z. mobilis (Additional file 2), synthesized and cloned into the vector pEZ15Asp [15] under the control of the pyruvate decarboxylase promoter (PDC) by GenScript (Piscataway, NJ, USA). These included Erwinia amylovora (Ea), Myroides odoratimimus (Ma), 
Staphylococcus warneri (Sw), Thermococcus gammatolerans (Tg), A. vinelandii (Av), Mycobacterium Smegmatis (Ms), Micrococcus luteus (Ml), A. tumefaciens (At), S. marcescens (Sm), Streptomyces coelicolor (Sc), and Dickeya dadantii $(D d)$. Prior to transformation, these plasmids were transformed into a Dam- Dcm- E. coli strain to avoid methylation to the DNA. These plasmids were transformed into the $Z$. mobilis $9 \mathrm{C}$ strain using the protocol described in Yang et al. [15]. Briefly, $1 \mu \mathrm{g}$ of plasmid DNA was mixed with $50 \mu \mathrm{L}$ of freshly thawed competent cells in a $0.1 \mathrm{~cm}$ gap electroporation cuvette on ice. Cells were electroporated using a Bio-Rad Gene Pulser (BioRad Laboratories, Inc. Hercules, CA, USA) using the following settings: $200 \Omega, 25 \mu \mathrm{F}, 1.6 \mathrm{kV}$. The tubes were immediately transferred to ice for cooling. One milliliter of mating medium (MM; $50 \mathrm{~g} / \mathrm{L}$ glucose, $10 \mathrm{~g} / \mathrm{L}$ yeast

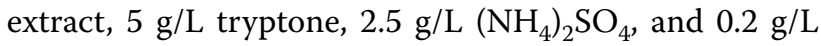
$\mathrm{K}_{2} \mathrm{HPO}_{4}$ containing $1 \mathrm{mM} \mathrm{MgSO} 4$ was added to the tube, the liquid transferred to a $1 \mathrm{~mL}$ cryovial and then incubated for $5-6 \mathrm{~h}$ at $30^{\circ} \mathrm{C}$ to allow cell recovery. Cells were then plated on $\mathrm{MM}$ agar containing spectinomycin $(200 \mu \mathrm{g} / \mathrm{mL})$ and incubated in an anaerobic jar (containing a gas pak) at $30^{\circ} \mathrm{C}$ for 2 days. Individual colonies were restreaked on $\mathrm{MM}$ medium containing spectinomycin followed by colony PCR to check for the presence of the $b d h$ gene. Colony PCR was carried out using the forward primer, SV-90, and the reverse primer, SV-91. All primers used in this study are available in Additional file 7. These primers flanked the promoter and terminator sequences, respectively, thereby amplifying the complete gene cassette.

\section{Construction of Bdh variants for crystal structure assessment}

Two different primers SV-161 and SV-162 were used to amplify the pEZ15Asp plasmid containing the Smbdh gene, such that a $6 \mathrm{X}$-histidine tag and a Tobacco etch virus protease cleavage site (ENLYFQG) sequences were introduced, in that order, immediately following the start codon of the $S m b d h$ gene. The PCR product was subjected to $D p n I$ digestion followed by ligation using the In-Fusion Cloning protocol (Takara Bio USA, Inc., Mountain View, CA, USA) to obtain the final plasmid, which will be henceforth referred to as "N-term SmBdh".

The Q247A SmBdh mutant was generated by amplifying the N-terminal His-TEV-Smbdh containing vector with primers SV-274 and SV-275 to introduce the Q247A mutation within the $b d h$ coding fragment, while amplifying the entire plasmid. This PCR product was then subjected to $D p n I$ treatment followed by recircularization using the In-Fusion Cloning protocol to obtain the final plasmid.
The double mutant, Q247A + V139Q SmBdh, was generated by amplifying the Q247A $S m b d h$ plasmid with primers SV-279 and SV-280. Following DpnI treatment, the PCR product was self-ligated using the In-Fusion Cloning protocol to obtain the final plasmid.

The 11aa-Ins-SmBdh mutant was constructed by amplifying the N-term $S m B d h$ plasmid with primers SV-277 and SV-276 to introduce the Enterobacter cloacae Bdh (EcBdh) 14 amino acid coding sequence "SEAAGKPLGYGTET" replacing 3 amino acids from $S m B d h$ ("RDK") into the Smbdh gene along with amplification of the entire vector. This PCR product was subjected to $D p n I$ treatment followed by self-ligation using the InFusion Cloning protocol. Prior to cloning the 14 amino acid sequence, the respective $E$ cloacae sequence was codon-optimized for expression in Z. mobilis.

In order to introduce a $6 \mathrm{X}$-histidine tag and a TEV protease cleavage site into the $\mathrm{N}$-terminal end of the $E$. cloacae $\mathrm{Bdh}(\mathrm{N}$-term $E c \mathrm{Bdh})$, the untagged version of the $E c b d h$ gene was first amplified from a previously transformed Z. mobilis strain BC-11B [15] using the primers SV-285 and SV-286. The vector fragment was obtained by amplifying pEZ15Asp-Smbdh vector with primers SV-283 and SV-284 followed by DpnI treatment of the PCR product. Both these fragments were ligated using the In-Fusion Cloning protocol to obtain the Ecbdh gene in the same expression vector, pEZ15Asp. The N-terminal histidine tag along with the TEV site was then introduced by amplifying the pEZ-15Asp-Ecbdh vector with primers SV-293 and SV-294, followed by DpnI treatment of the PCR product and self-ligation by the In-Fusion Cloning protocol.

The 11 amino acid deleted version of the $E c b d h$ gene (11aa-del-EcBdh) was cloned by amplifying the $\mathrm{N}$-term Ecbdh plasmid with primers SV-302 and SV-303 to amplify the entire plasmid, except the 14 amino acid sequence ("SEAAGKPLGYGTET") of EcBdh, while replacing this segment with a 3 amino acid sequence ("RDK") of SmBdh. Following amplification of the entire plasmid, this PCR product was subjected to $D p n I$ treatment followed by circularization using the In-Fusion Cloning protocol.

\section{Bdh protein expression and purification}

Following confirmation of the strains for the presence of the $b d h$ genes, individual colonies were inoculated into $5 \mathrm{~mL}$ RMG medium containing $200 \mu \mathrm{g} / \mathrm{mL}$ spectinomycin and incubated at $30^{\circ} \mathrm{C}$ for 2 days under shaking conditions $(120 \mathrm{rpm})$. An aliquot of this pre-grown culture was then transferred to $20 \mathrm{~mL}$ RMG medium containing $200 \mu \mathrm{g} / \mathrm{mL}$ spectinomycin for small scale protein extraction and activity analysis. For large-scale protein purification studies, $750 \mathrm{~mL}$ cultures were started in duplicates. 
In both cases, the starting $\mathrm{OD}_{600}$ of the cultures were adjusted to 0.025 . Cultures were incubated at $120 \mathrm{rpm}$ at $30{ }^{\circ} \mathrm{C}$ for 3 days. The final $\mathrm{OD}_{600}$ of the cultures were between 3 and 6 for the different cultures. Cultures were then transferred to ice prior to centrifugation at $6000 \times g$ for 5 min to obtain cell pellets. Cells were immediately frozen in liquid nitrogen prior to further processing.

For small-scale protein extraction, cells were thawed on ice and resuspended on $1 \mathrm{~mL}$ of $100 \mathrm{mM}$ phosphate buffer ( $\mathrm{pH}$ 7.0) containing protease inhibitor cocktail (Sigma-Aldrich Corp. St. Louis, MO, USA). Cells were disrupted by sonication using four cycles of $30 \mathrm{~s}$ pulses, with intermittent cooling on ice for $30 \mathrm{~s}$ between cycles. Cells were then subjected to bead beating for $10 \mathrm{~min}$ at $4{ }^{\circ} \mathrm{C}$ to ensure complete lysis of the cells. Protein extract was clarified by centrifugation at $13,000 \times g$ for $10 \mathrm{~min}$. Total protein content was estimated using the Bradford reagent protocol (Bio-Rad Laboratories, Inc. Hercules, CA, USA).

For large-scale protein extraction, frozen cell pellets were thawed and resuspended at room temperature with equal volume of buffer $(50 \mathrm{mM}$ Tris $\mathrm{pH} 7.5$, $100 \mathrm{mM} \mathrm{NaCl}$ and $10 \mathrm{mM}$ imidazole) and lysed using lysozyme and vortexing with glass beads. Specifically, $1 \mathrm{mg} / \mathrm{mL}$ lysozyme (Hampton Research, Aliso Viejo, CA, USA), $1 \mathrm{U} / \mathrm{mL}$ Pierce Universal Nuclease (Thermo Scientific, Rockford, IL, USA) and EDTA-free protease inhibitor (Thermo Scientific, Rockford, IL,USA according to manufacturer instructions) were added and the lysis mixture was incubated for $30 \mathrm{~min}$ at room temperature. Lysis was completed via vortexing with glass beads (0.1 $\mathrm{mm}$ diameter, 1:1 volume with the cell pellet) for 3-5 min and cell debris was removed by centrifugation for $15 \mathrm{~min}$ at $22,000 \times g$. The resulting supernatant was loaded into a 5-mL HisTrap FF crude column (GE Life Sciences, Piscataway, NJ, USA) using an Akta FPLC system (GE Life Sciences, Piscataway, NJ, USA) in $50 \mathrm{mM}$ Tris $\mathrm{pH}$ 7.5, $100 \mathrm{mM} \mathrm{NaCl}$ and $10 \mathrm{mM}$ imidazole. After loading and washing the unbound proteins from the column, the target proteins were eluted using $50 \mathrm{mM}$ Tris $\mathrm{pH} 7.5,100 \mathrm{mM} \mathrm{NaCl}$ and $250 \mathrm{mM}$ imidazole. Minor impurities were removed by size exclusion chromatography using HiLoad Superdex 75 (26/60) (GE Life Sciences, Piscataway, NJ, USA) in $20 \mathrm{mM}$ Tris $\mathrm{pH} 7.5$ and $100 \mathrm{mM} \mathrm{NaCl}$. Peaks corresponding to the Bdh samples were pooled and concentrated to $5-15 \mathrm{mg} / \mathrm{mL}$. Protein concentration was measured using absorbance at $280 \mathrm{~nm}$ in a NanoDrop 1000 and the protein-specific extinction coefficients and molecular weights.

\section{Protein crystallization}

Initial screening was done in a sitting drop vapor diffusion setup using a 96-well plate with Crystal Screen HT,
PEG/Ion HT and Grid Screen Salt HT from Hampton Research (Aliso Viejo, CA, USA). Fifty microlitre of well solution was added to the reservoir with three drops made of $0.2 \mu \mathrm{L}$ of well solution and $0.1 / 0.2 / 0.3 \mu \mathrm{L}$ of protein solution using a Phoenix crystallization robot (Art Robbins Instruments, Sunnyvale, CA, USA). The final crystals for all three structures were grown at $20^{\circ} \mathrm{C}$ using an optimization screen with $0.1 \mathrm{M}$ sodium malonate $\mathrm{pH}$ $6-7$ and $6-15 \% \mathrm{w} / \mathrm{v}$ polyethylene glycol 3350 as the well solution. The protein solution for WT SmBdh contained $9 \mathrm{mg} / \mathrm{mL}$ of protein, $20 \mathrm{mM}$ Tris $\mathrm{pH} 7.5,100 \mathrm{mM} \mathrm{NaCl}$, $20 \mathrm{mM} \mathrm{NAD}^{+}$and $200 \mathrm{mM}$ acetoin. SmBdh Q247A protein solution consisted of $4.2 \mathrm{mg} / \mathrm{mL}$ of protein, $20 \mathrm{mM}$ Tris $\mathrm{pH} 7.5,100 \mathrm{mM} \mathrm{NaCl}, 20 \mathrm{mM} \mathrm{NAD}^{+}$and $20 \mathrm{mM}$ acetoin. SmBdh Q247V + V139Q had $14.5 \mathrm{mg} / \mathrm{mL}$ of protein, $20 \mathrm{mM}$ Tris $\mathrm{pH}$ 7.5, $100 \mathrm{mM} \mathrm{NaCl}, 20 \mathrm{mM} \mathrm{NAD}^{+}$ and $20 \mathrm{mM}$ acetoin.

\section{Data collection and processing}

Before data collection the $S m B d h$ crystals were flash frozen in a nitrogen gas stream at $100 \mathrm{~K}$ followed by data collection using an in-house Bruker X8 MicroStar X-Ray generator with Helios mirrors and a Bruker Platinum 135 CCD detector (Bruker AXS LLC, Madison, WI, USA. SmBdh Q247A and SmBdh Q247V+V139Q crystals were further protected from ice formation by shortly moving them into a well solution drop with $15 \%(\mathrm{v} / \mathrm{v})$ ethylene glycol and 15\% (v/v) glycerol for improved cryo protection. Bruker Suite of programs version 2014-9 (Bruker AXS LLC, Madison, WI, USA) was used for data indexing and processing.

\section{Structure solution and refinement}

The CCP4 package of programs [48] was used for converting intensities into structure factors, for project tracking, and access to the individual programs. Five percent of reflections were reserved for $R_{\text {free }}$ calculations using programs F2MTZ, Truncate, CAD and Unique. The structure of the WT $S m B d h$ was determined via molecular replacement using MOLREP [49]. The initial model was built based on PDB entry 4ni5 with FFAS03 search and ProtMod modeling servers [50-52] using the SCWRL method. The resulting model was refined in REFMAC5 [53] version 5.8.0258 and rebuilt and inspected using Coot version 0.8.0.2 [54]. Structures of the SmBdh Q247A mutant and Q247A+V139Q double mutant were determined via molecular replacement as described above using the WT SmBdh as a model. Ramachandran plot was calculated with MOLPROBITY [55] and root mean square deviations (r.m.s.d.) of bond lengths and angles were calculated using ideal values of Engh and Huber stereochemical parameters [56]. Wilson 
Table 3 X-ray data collection and refinement statistics

\begin{tabular}{|c|c|c|c|}
\hline & WT SmBDH & SmBDH Q247A & SmBDH Q247A + V139Q \\
\hline \multicolumn{4}{|l|}{ Data collection } \\
\hline Space group & $\mathrm{P}_{4} \mathrm{2}_{1} \mathrm{2}$ & $\mathrm{P}_{4} \mathrm{2}_{1} 2$ & $\mathrm{P}_{4} \mathrm{2}_{1} 2$ \\
\hline Unit cell $\left(\AA,{ }^{\circ}\right)$ & $\begin{array}{l}a=b=108.17, c=82.88 \\
a=\beta=\gamma=90.00\end{array}$ & $\begin{array}{l}a=b=108.68, c=82.95 \\
a=\beta=\gamma=90.0\end{array}$ & $\begin{array}{l}a=b=108.80, c=83.11 \\
a=\beta=\gamma=90.0\end{array}$ \\
\hline Wavelength $(\AA)$ & 1.54178 & 1.54178 & 1.54178 \\
\hline Temperature (K) & 100 & 100 & 100 \\
\hline Resolution (Å) & $25.0-2.0(2.1-2.0)$ & $25.0-1.9(2.0-1.9)$ & $25.0-1.8(1.9-1.8)$ \\
\hline Unique reflections & $33,823(4496)$ & $39,724(5531)$ & $46,796(6911)$ \\
\hline$R_{\text {int }}{ }^{\mathrm{a}}$ & $0.138(0.689)$ & $0.109(0.748)$ & $0.093(0.793)$ \\
\hline Average redundancy & $11.4(8.8)$ & $17.3(10.6)$ & $17.0(12.5)$ \\
\hline$<\mid>/<\sigma(\mid)>$ & $11.2(2.0)$ & $18.7(2.6)$ & $21.7(1.9)$ \\
\hline Completeness (\%) & $100(100)$ & $100(100)$ & $100(100)$ \\
\hline \multicolumn{4}{|l|}{ Refinement } \\
\hline$R / R_{\text {free }}$ & $0.162(0.214) / 0.279(0.378)$ & $0.168(0.340) / 0.222(0.347)$ & $0.160(0.210) / 0.295(0.342)$ \\
\hline Protein atoms & 3736 & 3792 & 3766 \\
\hline Water molecules & 432 & 551 & 558 \\
\hline Other atoms & 141 & 151 & 70 \\
\hline r.m.s.d. from ideal bond length $(\AA)$ & 0.010 & 0.009 & 0.010 \\
\hline r.m.s.d. from ideal bond angles ${ }^{b}\left(^{\circ}\right)$ & 1.497 & 1.486 & 1.612 \\
\hline Wilson B-factor & 21.6 & 19.5 & 21.2 \\
\hline Average B-factor for protein atoms $\left(\AA^{2}\right)$ & 25.2 & 25.0 & 24.0 \\
\hline Average B-factor for water molecules $\left(\AA^{2}\right)$ & 33.0 & 32.6 & 33.1 \\
\hline \multicolumn{4}{|l|}{ Ramachandran plot statistics ${ }^{\mathrm{C}}(\%)$} \\
\hline Allowed & 99.8 & 99.8 & 99.8 \\
\hline Favored & 96.9 & 97.2 & 97.3 \\
\hline Number of outliers & 1 & 1 & 1 \\
\hline
\end{tabular}

Statistics for the highest resolution bin are shown in parenthesis

${ }^{a} R_{\text {int }}=\sum \mathrm{hkl} \sum \mathrm{i}|\mathrm{li}(\mathrm{hkl})-\langle\mathrm{l}(\mathrm{hkl})\rangle| / \sum \mathrm{hkl} \sum \mathrm{i}$ li(hkl), where li(hkl) is the intensity of an individual reflection and $\langle(\mathrm{hkl})>$ is the mean intensity of a group of equivalents; the sums are calculated over all reflections with more than one equivalent measured

b [56]

c [55]

B-factor was obtained from CTRUNCATE [48] version 1.0.11. All structures have been deposited to the Protein Data Bank with PDB codes 6XEW (WT SmBdh), 6VSP (SmBdh Q247A), and 6XEX (SmBdh Q247A+V139Q). Data collection and refinement statistics are shown in Table 3.

\section{Bdh activity analysis}

Bdh activity was assayed by following NADH oxidation at $340 \mathrm{~nm}$ for 5 min using a molar extinction coefficient of $6.22 \mathrm{mM}^{-1} \mathrm{~cm}^{-1}$. The enzyme reaction was carried out in a total volume of $200 \mu \mathrm{L}$ and contained $100 \mathrm{mM}$ potassium phosphate buffer ( $\mathrm{pH} 7.0$ ), $0.25 \mathrm{mM} \mathrm{NADH}$ and $25 \mathrm{mM}$ acetoin. The reaction was started by addition of the enzyme. All reactions were carried out in microtiter plates and monitored using a FLUOstar Omega plate reader (BMG Labtech $\mathrm{GmbH}$, Ortenburg, Germany). Enzyme activities were represented as unit per nmol of the purified protein. One unit of enzyme was defined as the amount of enzyme that consumed one micromole of $\mathrm{NADH}$ per minute. For total proteins, enzyme activities were represented as micromole of NADH consumed per min per $\mathrm{mg}$ of total protein.

For phylogenetic screening of the Bdh enzymes, whole cell extracts obtained from the small-scale extraction procedure were used for enzyme assays. A range of concentrations from 1-20 $\mu \mathrm{g}$ total protein were tested for each protein extract. For the Bdh assays involving purified proteins ( $S m B d h$ and $E c B d h$ ), a range of protein concentrations from $0.05-1 \mu \mathrm{g}$ were used. 


\section{Supplementary information}

Supplementary information accompanies this paper at https://doi. org/10.1186/s13068-020-01820-x.

Additional file 1. PCR analysis of Z. mobilis tranformants containing the different Bdh genes. Eleven Bdh genes were transformed into Z. mobilis strain $9 \mathrm{C}$ and plated on RMG medium containing spectinomycin. Eight independent colonies were selected for colony PCR analysis using gene specific primers. Five microliters of the PCR products were run on $1 \%$ agarose gel and visualized using FluoChem Gel analyzer. White bar represents sets of 8 lanes for each Bdh gene. Av, Azotobacter vinelandii; Ml, Micrococcus luteus; Ea, Erwinia amylovora; Sw, Staphylococcus warneri; Sc, Streptomyces coelicolor; Sm, Serratia marcescens; Dd, Dickeya dadantii; Tg, Thermococcus gammatolerans; At, Agrobacterium tumefaciens; Ms, Mycobacterium Smegmatis; Mo, Myroides odoratimimus; 9c, Z. mobilis control strain.

Additional file 2. BDH genes selected for expression in Z. mobilis.

Additional file 3. Detection of heterologous Bdh proteins from Z. mobilis transformants using total protein staining. Five independent transformant colonies were selected for protein extraction. Total proteins were separated on 4-12\% SDS PAGE gel followed by Coomassie staining. Arrows represent the expected molecular weight of the individual Bdh proteins. Two Bdh protein sets are shown in each PAGE gel. Each protein set is represented by 5 lanes as indicated by the black bars. Bdh protein names are shown above the black bars. Av, Azotobacter vinelandii; MI, Micrococcus luteus; Ea, Erwinia amylovora; Sw, Staphylococcus warneri; Sc, Streptomyces coelicolor; Sm, Serratia marcescens; Dd, Dickeya dadantii; Tg. Thermococcus gammatolerans; At, Agrobacterium tumefaciens; Ms, Mycobacterium Smegmatis; Mo, Myroides odoratimimus; C, Z. mobilis control strain.

Additional file 4. Ala93Ca-Trp192Ca distance in 'open' and 'closed' molecules, $\AA$.

Additional file 5. Multiple alignment of $\mathrm{N}$-terminal histidine tagged SmBdh sequences representing the sites of amino acid changes. Three different versions of $S m B d h$ are shown. Boxes indicate the amino acids that were replaced in the other mutants. SmBdh (N-term), wild-type; Q247A-SmBdh (N-term) and Q247A+V139Q-SmBdh (N-term), two different variants of $S m B d h$.

Additional file 6. 2,3-butanediol dehydrogenase gene sequences used in the study.

Additional file 7. Primers used in this study.

\section{Abbreviations}

2,3-BDO: 2,3-butanediol; Bdh: 2,3-butanediol dehydrogenase; NAD: Nicotinamide adenine dinucleotide (oxidized); NADH: Nicotinamide adenine dinucleotide (reduced); Als: Acetolactate synthase; Ndh: NADH oxidase; PDB: Protein data bank; SDR: Short-chain dehydrogenase/reductase; PCR: Polymerase chain reaction; a6: Alpha 6 helix; KpBdh: Klebsiella pneumoniae Bdh; GoBdh: Gluconobacter oxydans Bdh; BcBdh: Burkholderia cenocepacea Bdh; BxBdh: Burkholderia xenovorans Bdh; CgBdh: Corynebacterium glutamicum Bdh; SmBdh: Serratia marcescens Bdh; EcBdh: Enterobacter cloacae Bdh; Ea: Erwinia amylovora; Ma: Myroides odoratimimus; Sw: Staphylococcus warneri; Tg: Thermococcus gammatolerans; Av: Azotobacter vinelandii; Ms: Mycobacterium smegmatis; MI: Micrococcus luteus; At: Agrobacterium tumefaciens; Sc: Streptomyces coelicolor; Dd: Dickeya dadantii; GIn247: Glutamine 247; r.m.s.d.: Root mean square deviations; Q247A: Glutamine 247 to alanine; V139Q: Valine 139 to glutamine; RMG: Rich medium containing glucose.

\section{Acknowledgements}

This work was authored by the National Renewable Energy Laboratory, managed and operated by Alliance for Sustainable Energy, LLC for the U.S. Department of Energy (DOE) under Contract No. DE-AC36-08GO28308. Funding provided by U.S. Department of Energy Office of Energy Efficiency and Renewable Energy Bioenergy Technologies Office under contract DE-AC3608GO28308. The views expressed in the article do not necessarily represent the views of the DOE or the U.S. Government. The U.S. Government retains and the publisher, by accepting the article for publication, acknowledges that the U.S. Government retains a nonexclusive, paid-up, irrevocable, worldwide license to publish or reproduce the published form of this work, or allow others to do so, for U.S. Government purposes. YBC was supported by Indo-US Science and Technology forum (IUSSTF) - Bioenergy-Awards for Cutting Edge Research (B-ACER) grant, Govt. of India. The authors would like to thank Dr. Shihui Yang for providing the control plasmids pEZ-15Asp-EcBdh, pEZ-15AspL/Bdh and pEZ15Asp-KpBdh used in this study. The authors also thank Mary Ann Franden and Yat-Chen Chou of the National Renewable Energy Laboratory for helpful technical discussions.

\section{Authors' contributions}

VS wrote the paper, designed Bdh constructs, and performed enzyme assays; VL wrote the paper, designed Bdh mutant constructs, crystallized and determined the crystal structures of Bdh proteins; SF, KL, AH and YBC carried out plasmid cloning, transformations, small and large-scale culture growths, protein extractions, and DNA and protein gel electrophoresis; MA was in involved in crystallization and structure determination of the Bdh proteins; SD and $\mathrm{MH}$ managed the project and were involved in editing the manuscript. All authors read and approved the final manuscript.

\section{Funding}

Funding provided by U.S. Department of Energy Office of Energy Efficiency and Renewable Energy Bioenergy Technologies Office under contract DE-AC36-08GO28308.

\section{Availability of data and materials}

All data generated or analyzed during this study are included in this published article and its supplementary information files.

\section{Ethics and approval and consent to participate}

Not applicable.

\section{Consent for publication \\ Not applicable.}

\section{Competing interests}

Provisional patent filed on Bdh modifications.

\section{Author details}

${ }_{1}^{1}$ Biosciences Center, National Renewable Energy Laboratory, 15013 Denver West Parkway, Golden, CO 80401, USA. ${ }^{2}$ Biodiversity and Ecosystem Research, Institute of Advanced Study in Science and Technology (IASST), Guwahati, Assam, India.

Received: 1 July 2020 Accepted: 21 October 2020

Published online: 10 November 2020

\section{References}

1. Bialkowska AM. Strategies for efficient and economical 2,3-butanediol production: new trends in this field. World J Microbiol Biotechnol. 2016;32(12):200.

2. Hakizimana $\mathrm{O}$, Matabaro $\mathrm{E}$, Lee $\mathrm{BH}$. The current strategies and parameters for the enhanced microbial production of 2,3-butanediol. Biotechnol Rep. 2020;25:e00397.

3. Prescott SC, Dunn CG. The production and properties of 2,3-butanediol. In: Foster JW, editor. Industrial microbiology. New York: McGraw-Hill; 1949. p. $487-523$

4. Sabra W, Groeger C, Zeng AP. Microbial cell factories for Diol production. Adv Biochem Eng Biotechnol. 2016;155:165-97.

5. Juni E, Heym GA. A cyclic pathway for the bacterial dissimilation of 2, 3-butanediol, acetylmethylcarbinol, and diacetyl. I. General aspects of the 2, 3-butanediol cycle. J Bacteriol. 1956;71(4):425-32.

6. Syu MJ. Biological production of 2,3-butanediol. Appl Microbiol Biotechnol. 2001;55(1):10-8.

7. Xiao Z, Xu P. Acetoin metabolism in bacteria. Crit Rev Microbiol. 2007;33(2):127-40.

8. Ji XJ, Huang H, Ouyang PK. Microbial 2,3-butanediol production: a stateof-the-art review. Biotechnol Adv. 2011;29(3):351-64. 
9. Song CW, Park JM, Chung SC, Lee SY, Song H. Microbial production of 2,3-butanediol for industrial applications. J Ind Microbiol Biotechnol. 2019:46(11):1583-601.

10. Kandasamy V, Liu J, Dantoft SH, Solem C, Jensen PR. Synthesis of (3R)-acetoin and 2,3-butanediol isomers by metabolically engineered Lactococcus lactis. Sci Rep. 2016;6:36769.

11. Kim JW, Kim J, Seo SO, Kim KH, Jin YS, Seo JH. Enhanced production of 2,3-butanediol by engineered Saccharomyces cerevisiae through fine-tuning of pyruvate decarboxylase and NADH oxidase activities. Biotechnol Biofuels. 2016;9:265

12. Oliver JW, Machado IM, Yoneda H, Atsumi S. Cyanobacterial conversion of carbon dioxide to 2,3-butanediol. Proc Natl Acad Sci USA. 2013;110(4):1249-54.

13. Xu Y, Chu H, Gao C, Tao F, Zhou Z, Li K, et al. Systematic metabolic engineering of Escherichia coli for high-yield production of fuel bio-chemical 2,3-butanediol. Metab Eng. 2014;23:22-33.

14. Jeffries TW. Ethanol fermentation on the move. Nat Biotechnol. 2005;23(1):40-1.

15. Yang S, Mohagheghi A, Franden MA, Chou YC, Chen X, Dowe N, et al. Metabolic engineering of Zymomonas mobilis for 2,3-butanediol production from lignocellulosic biomass sugars. Biotechnol Biofuels. 2016;9(1):189.

16. Chen X, Kuhn E, Jennings E, Nelson N, Tao L, Zhang M, et al. DMR (deacetylation and mechanical refining) processing of corn stover achieves high monomeric sugar concentrations ( $230 \mathrm{~g} / \mathrm{L})$ during enzymatic hydrolysis and high ethanol concentration $(>10 \% \mathrm{v} / \mathrm{v})$ during fermentation without hydrolyzate purification or concentration. Energy Environ Sci. 2016:9:1237-45.

17. Zhang X, Bao T, Rao Z, Yang T, Xu Z, Yang $S$, et al. Two-stage pH control strategy based on the $\mathrm{pH}$ preference of acetoin reductase regulates acetoin and 2,3-butanediol distribution in Bacillus subtilis. PLoS ONE. 2014;9(3):e91187.

18. Zhang L, Xu Q, Zhan S, Li Y, Lin H, Sun S, et al. A new NAD(H)-dependent meso-2,3-butanediol dehydrogenase from an industrially potential strain Serratia marcescens H30. Appl Microbiol Biotechnol. 2014;98(3):1175-84.

19. Berman HM, Westbrook J, Feng Z, Gilliland G, Bhat TN, Weissig H, et al. The Protein Data Bank. Nucleic Acids Res. 2000;28(1):235-42.

20. Hedlund J, Jornvall H, Persson B. Subdivision of the MDR superfamily of medium-chain dehydrogenases/reductases through iterative hidden Markov model refinement. BMC Bioinformatics. 2010;11:534.

21. Knoll M, Pleiss J. The Medium-Chain Dehydrogenase/reductase Engineering Database: a systematic analysis of a diverse protein family to understand sequence-structure-function relationship. Protein Sci. 2008;17(10):1689-97.

22 Nordling E, Jornvall H, Persson B. Medium-chain dehydrogenases/reductases (MDR). Family characterizations including genome comparisons and active site modeling. Eur J Biochem. 2002;269(17):4267-76.

23. Persson B, Hedlund J, Jornvall H. Medium- and short-chain dehydrogenase/ reductase gene and protein families: the MDR superfamily. Cell Mol Life Sci. 2008;65(24):3879-94.

24 Gonzalez E, Fernandez MR, Larroy C, Sola L, Pericas MA, Pares X, et al. Characterization of a (2R,3R)-2,3-butanediol dehydrogenase as the Saccharomyces cerevisiae YAL060W gene product. Disruption and induction of the gene. J Biol Chem. 2000;275(46):35876-85.

25. Huang M, Oppermann FB, Steinbuchel A. Molecular characterization of the Pseudomonas putida 2,3-butanediol catabolic pathway. FEMS Microbiol Lett. 1994;124(2):141-50.

26. Li L, Zhang L, Li K, Wang Y, Gao C, Han B, et al. A newly isolated Bacillus licheniformis strain thermophilically produces 2,3-butanediol, a platform and fuel bio-chemical. Biotechnol Biofuels. 2013;6(1):123.

27. Lu C, Ge Y, Cao M, Guo X, Liu P, Gao C, et al. Metabolic engineering of Bacillus licheniformis for production of acetoin. Front Bioeng Biotechnol. 2020;8:125.

28. Kavanagh KL, Jornvall H, Persson B, Oppermann U. Medium- and shortchain dehydrogenase/reductase gene and protein families: the SDR superfamily: functional and structural diversity within a family of metabolic and regulatory enzymes. Cell Mol Life Sci. 2008;65(24):3895-906.

29. Jörnvall H, Persson B, Krook M, Atrian S, Gonzalez-Duarte R, Jeffery J, et al. Short-chain dehydrogenases/reductases (SDR). Biochemistry. 1995;34(18):6003-13.

30. Otagiri M, Kurisu G, Ui S, Takusagawa Y, Ohkuma M, Kudo T, et al. Crystal structure of meso-2,3-butanediol dehydrogenase in a complex with NAD+ and inhibitor mercaptoethanol at $1.7 \mathrm{~A}$ resolution for understanding of chiral substrate recognition mechanisms. J Biochem. 2001;129(2):205-8.
31. Otagiri M, Ui S, Takusagawa Y, Ohtsuki T, Kurisu G, Kusunoki M. Structural basis for chiral substrate recognition by two 2,3-butanediol dehydrogenases. FEBS Lett. 2010;584(1):219-23.

32. Li L, Wang Y, Zhang L, Ma C, Wang A, Tao F, et al. Biocatalytic production of (2S,3S)-2,3-butanediol from diacetyl using whole cells of engineered Escherichia coli. Bioresour Technol. 2012;115:111-6.

33. Yan $Y$, Lee CC, Liao JC. Enantioselective synthesis of pure ( $R, R)$-2,3-butanediol in Escherichia coli with stereospecific secondary alcohol dehydrogenases. Org Biomol Chem. 2009;7(19):3914-7.

34. Zhang M, Eddy C, Deanda K, Finkelstein M, Picataggio S. Metabolic engineering of a pentose metabolism pathway in ethanologenic Zymomonas mobilis. Science. 1995;267(5195):240-3.

35. Krissinel E, Henrick K. Inference of macromolecular assemblies from crystalline state. J Mol Biol. 2007;372(3):774-97.

36. Médici R, Stammes H, Kwakernaak S, Otten LG, Hanefeld U. Assessing the stereoselectivity of Serratia marcescens CECT 977 2,3-butanediol dehydrogenase. Catal Sci Technol. 2017;7:1831-7.

37. Krissinel E, Henrick K. Secondary-structure matching (SSM), a new tool for fast protein structure alignment in three dimensions. Acta Crystallogr D Biol Crystallogr. 2004;60(Pt 12 Pt 1):2256-68.

38. Yu M, Huang M, Song Q, Shao J, Ying X. Characterization of a (2R,3R)-2,3-butanediol dehydrogenase from Rhodococcus erythropolis WZ010. Molecules. 2015;20(4):7156-73.

39. Rados D, Turner DL, Catarino T, Hoffart E, Neves AR, Eikmanns BJ, et al. Stereospecificity of Corynebacterium glutamicum 2,3-butanediol dehydrogenase and implications for the stereochemical purity of bioproduced 2,3-butanediol. Appl Microbiol Biotechnol. 2016;100(24):10573-83.

40. Braun F, Bertoletti N, Moller G, Adamski J, Steinmetzer T, Salah M, et al. First structure-activity relationship of 17beta-hydroxysteroid dehydrogenase type 14 nonsteroidal inhibitors and crystal structures in complex with the enzyme. J Med Chem. 2016;59(23):10719-37.

41. Lukacik P, Keller B, Bunkoczi G, Kavanagh KL, Lee WH, Adamski J, et al. Structural and biochemical characterization of human orphan DHRS10 reveals a novel cytosolic enzyme with steroid dehydrogenase activity. Biochem J. 2007:402(3):419-27.

42 Shanati T, Lockie C, Beloti L, Grogan G, Ansorge-Schumacher MB. Two enantiocomplementary ephedrine dehydrogenases from Arthrobacter sp. TS-15 with broad substrate specificity. ACS Catal. 2019;9(7):6202-11.

43. Nishioka T, Yasutake Y, Nishiya Y, Tamura T. Structure-guided mutagenesis for the improvement of substrate specificity of Bacillus megaterium glucose 1-dehydrogenase IV. FEBS J. 2012;279(17):3264-75.

44. Kumar S, Stecher G, Li M, Knyaz C, Tamura K. MEGA X: molecular evolutionary genetics analysis across computing platforms. Mol Biol Evol. 2018;35(6):1547-9.

45. Saitou N, Nei M. The neighbor-joining method: a new method for reconstructing phylogenetic trees. Mol Biol Evol. 1987;4(4):406-25.

46. Felsenstein J. Confidence limits on phylogenies: an approach using the bootstrap. Evolution. 1985;39(4):783-91.

47. Zuckerkandl E, Pauling L. Molecules as documents of evolutionary history. J Theor Biol. 1965;8(2):357-66.

48. Winn MD, Ballard CC, Cowtan KD, Dodson EJ, Emsley P, Evans PR, et al. Overview of the CCP4 suite and current developments. Acta Crystallogr D Biol Crystallogr. 2011:67(Pt 4):235-42.

49. Vagin A, Teplyakov A. Molecular replacement with MOLREP. Acta Crystallogr D Biol Crystallogr. 2010;66(Pt 1):22-5.

50 Jaroszewski L, Li Z, Cai XH, Weber C, Godzik A. FFAS server: novel features and applications. Nucleic Acids Res. 2011;39(Web Server issue):W38-44.

51 Jaroszewski L, Rychlewski L, Li Z, Li W, Godzik A. FFAS03: a server for profile-profile sequence alignments. Nucleic Acids Res. 2005;33(Web Server issue):W284-288.

52. Xu D, Jaroszewski L, Li Z, Godzik A. FFAS-3D: improving fold recognition by including optimized structural features and template re-ranking. Bioinformatics. 2014;30(5):660-7.

53. Murshudov GN, Skubak P, Lebedev AA, Pannu NS, Steiner RA, Nicholls RA, et al. REFMAC5 for the refinement of macromolecular crystal structures. Acta Crystallogr D Biol Crystallogr. 2011;67(Pt 4):355-67.

54. Emsley P, Lohkamp B, ScottWG, Cowtan K. Features and development of Coot. Acta Crystallogr D Biol Crystallogr. 2010;66(Pt 4):486-501. 
55. Chen VB, Arendall WB 3rd, Headd JJ, Keedy DA, Immormino RM, Kapral GJ, et al. MolProbity: all-atom structure validation for macromolecular crystallography. Acta Crystallogr D Biol Crystallogr. 2010;66(Pt 1):12-21.

56. Engh RA, Huber R. Accurate bond and angle parameters for X-Ray proteinstructure refinement. Acta Crystallographica Section A. 1991;47:392-400.

\section{Publisher's Note}

Springer Nature remains neutral with regard to jurisdictional claims in published maps and institutional affiliations.
Ready to submit your research? Choose BMC and benefit from:

- fast, convenient online submission

- thorough peer review by experienced researchers in your field

- rapid publication on acceptance

- support for research data, including large and complex data types

- gold Open Access which fosters wider collaboration and increased citations

- maximum visibility for your research: over $100 \mathrm{M}$ website views per year

At BMC, research is always in progress.

Learn more biomedcentral.com/submissions 